\title{
Neuroendocrine and physiological regulation of intake with particular reference to domesticated ruminant animals
}

\author{
John R. Roche ${ }^{1,2} *$, Dominique Blache ${ }^{3}$, Jane K. Kay ${ }^{1}$, Dale R. Miller ${ }^{2}$, Angela J. Sheahan ${ }^{1}$ and David W. Miller ${ }^{4}$ \\ ${ }^{1}$ DairyNZ Ltd, Hamilton, New Zealand \\ ${ }^{2}$ University of Tasmania, Tasmania, Australia \\ ${ }^{3}$ School of Animal Biology, University of Western Australia, Perth, Western Australia \\ ${ }^{4}$ Murdoch University, Perth, Western Australia
}

\begin{abstract}
The central nervous system undertakes the homeostatic role of sensing nutrient intake and body reserves, integrating the information, and regulating energy intake and/or energy expenditure. Few tasks regulated by the brain hold greater survival value, particularly important in farmed ruminant species, where the demands of pregnancy, lactation and/or growth are not easily met by often bulky plant-based and sometimes nutrient-sparse diets. Information regarding metabolic state can be transmitted to the appetite control centres of the brain by a diverse array of signals, such as stimulation of the vagus nerve, or metabolic 'feedback' factors derived from the pituitary gland, adipose tissue, stomach/abomasum, intestine, pancreas and/or muscle. These signals act directly on the neurons located in the arcuate nucleus of the medio-basal hypothalamus, a key integration, and hunger (orexigenic) and satiety (anorexigenic) control centre of the brain. Interest in human obesity and associated disorders has fuelled considerable research effort in this area, resulting in increased understanding of chronic and acute factors influencing feed intake. In recent years, research has demonstrated that these results have relevance to animal production, with genetic selection for production found to affect orexigenic hormones, feeding found to reduce the concentration of acute controllers of orexigenic signals, and exogenous administration of orexigenic hormones (i.e. growth hormone or ghrelin) reportedly increasing DM intake in ruminant animals as well as single-stomached species. The current state of knowledge on factors influencing the hypothalamic orexigenic and anorexigenic control centres is reviewed, particularly as it relates to domesticated ruminant animals, and potential avenues for future research are identified.
\end{abstract}

Neuroendocrine regulation: Intake: Hormones: Ruminants

\section{Introduction}

Forbes \& Provenza ${ }^{(1)}$ identified the challenge of understanding factors controlling food intake and diet selection as one that occupies a very important place in the fields of nutrition, physiology and psychology. DM intake is arguably the most important factor in ruminant animal production, dictating the amount of nutrients available for production and thereby dictating gross feed conversion efficiency (i.e. nutrients directed to production-related processes relative to those directed to maintenance). In pasture-based systems this limitation is even more important. Ulyatt \& Waghorn ${ }^{(2)}$ and Muller ${ }^{(3)}$ emphasised that the major limitation to dairy cow productivity in pasture-based dairy systems is the low DM intake of herbage, resulting in nutrient intakes that are insufficient to exploit the genetic capability of the lactating animal to utilise nutrients for milk production. This is consistent with the findings of Kolver \& Muller ${ }^{(4)}$, who reported that $60 \%$ of the difference in milk production between grazing cows

\footnotetext{
Abbreviations: AgRP, agouti-related protein; ARC, arcuate nucleus; BBB, blood-brain barrier; BCS, body condition score; $\mathrm{CB}$, cannabinoid; CCK, cholecystokinin; CNS, central nervous system; $\Delta^{9}$-THC, $\Delta^{9}$-tetrahydrocannabinol; GH, growth hormone; GHRP, growth hormone-releasing peptide; GHS-R, growth hormone secretagogue receptor; GI, gastrointestinal; GRF, growth hormone-releasing factor; icv, intracerebroventricular; IGF, insulin-like growth factor; NDF, neutral-detergent fibre; NPY, neuropeptide Y; NST, nucleus of the solitary tract; POMC, pro-opio-melanocortin; PP, pancreatic polypeptide; PYY, peptide YY; VFA, volatile fatty acid; VFI, voluntary feed intake.

*Corresponding author: Dr J. R. Roche, fax + 647 8583751, email john.roche@dairynz.co.nz
} 
and those fed total mixed rations in confinement was as a result of lower DM intake.

A further limitation to DM intake in grazing ruminant species is the occurrence of substitution, whereby an animal refuses a significant quantity of available pasture when offered a supplement (forage or grain), such that energy intake does not increase to the extent theoretically possible from the supplemented energy. Univariate and multivariate analyses accounting for forage, grain and animal characteristics that are practically measurable have only been able to account for $50 \%$ of the variation in substitution rate. However, Linnane et al. ${ }^{(5)}$ highlighted a hitherto unknown effect of cow genetics on substitution rate, suggesting that there were poorly understood and unevaluated animal factors affecting an animal's desire to eat. The association of metabolic disorders with low DM intake ${ }^{(6)}$ implicates a reduction in DM intake at key times with adverse health events, and is a further motivation for an increased understanding of intake regulation.

Van Soest ${ }^{(7)}$ highlighted the difficulties that ruminant animals present to the physiologist wishing to understand the mechanisms controlling DM intake. Physiological functions such as feed intake are regulated by multiple factors ${ }^{(8)}$. For example, the majority of domesticated ruminant animals have feed available almost continuously, irrespective of whether they are intensively managed, with feed supply under the direct control of the farm manager, or managed more extensively, where feed availability varies in quantity and quality according to the time of the year, but is rarely unavailable ${ }^{(9)}$. Despite this, DM intake is the primary limitation on production ${ }^{(4,10)}$. As a result, voluntary feed intake (VFI) of production animals (milk, meat and fibre) and the factors controlling it have received considerable attention over the decades. Until recently, the controlling factors were poorly understood, but there has been a dramatic growth in knowledge of important central and peripheral factors affecting the regulation of hunger and satiety. This applies particularly to the neurochemical components of brain systems influencing ingestive behaviours.

\section{Acute and chronic regulation of intake}

The terms 'appetite' and 'hunger' are often incorrectly used interchangeably. Hunger differs from appetite in that hunger is a physiological concept, whereas appetite is usually culturally defined. Appetite may be characterised by a mild hunger, but it is directed at a choice of food items, not a drive to eat per se, and often comes with the expectation of reward ${ }^{(11)}$. Forbes ${ }^{(9)}$ further defined appetite as 'a drive to eat a specific nutrient' rather than to eat food as such, suggesting that animals could determine the deficit or surplus of a specific nutrient in their diet, and indirectly suggesting that a specific nutrient could alter appetite. The depraved eating habits ${ }^{(12)}$ of animals clinically deficient in either $\mathrm{Na}$ or $\mathrm{P}$ (i.e. pica) may be consistent with an innate 'knowledge' of the particular nutrient deficiency associated with appetite. In comparison, hunger patterns are manifested in patterns of feeding behaviour, which are most probably a result of chemical and tactile stimuli altering specific regions of the brain.
Neither hunger nor appetite can be precisely measured; therefore, to determine the effect of a specific variable(s) on these factors, VFI is measured, as this is the result of both hunger and appetite and can be measured accurately. Regulation of VFI also needs to be considered on different time scales, from meal initiation and the regulation of meal size (short term/acute) to the longer-term (chronic) regulation of VFI required to maintain a physiological steady state. Acute controllers of VFI are most probably hormones (for example, insulin, adrenaline), whose concentrations are controlled by circulating metabolites (for example, glucose, fatty acids) and reflect the immediate energy status of the animal relative to metabolic demand. These circulating factors are required to have short halflives, exhibit significant variation throughout the day, and may even exhibit circadian rhythms, particularly in farmed animals with diurnal-type feeding behaviours (i.e. they are most active between sunrise and sunset). Chronic controllers of VFI, in comparison, are more likely to exhibit consistency in their circulating concentrations (little diurnal change), need not necessarily have short half-lives, and must provide information on the status of the body's long-term energy status (adipose tissue depots).

Food intake occurs in distinct bouts or meals, with the frequency and size of individual meals over the day comprising an individual's feeding pattern ${ }^{(13)}$. Most animals have habitual feeding patterns, consuming approximately the same number of meals at the same times each day. Such feeding behaviour is primarily a response to orexigenic and anorexigenic signals, although the factors that control when meals occur are probably different to those controlling meal cessation.

In general, farmed ruminant animals are typically diurnal and their feeding behaviour has been studied for more than 80 years. Time spent grazing/feeding, ruminating, and lying, as well as diurnal and temporal behaviour patterns have been extensively reviewed by Hafez \& Schein ${ }^{(14)}$ for cattle and Hafez \& Scott $^{(15)}$ for sheep and goats. In subsequent research, the effects of imposed treatments and genetic differences within species on animal behaviour ${ }^{(5,16)}$ have been measured, acknowledging the importance of animal behaviour, and in particular feeding behaviour, in explaining differences in animal production.

Assuming forage is not limiting, grazing cattle generally have four to five feeding bouts per $24 \mathrm{~h}$ period, with the most continuous periods of grazing occurring before dawn, in the early morning, mid afternoon, and just before sundown. In total, cattle graze for between 4 and $11 \mathrm{~h}^{(5,14,16)}$ and ruminate for a similar period. In comparison, cows fed total mixed rations indoors eat for a considerably shorter total period $\left(4-5 \mathrm{~h} / \mathrm{d}^{(17,18)}\right)$ than their grazing counterparts, but tend to feed more frequently $\left(9-14\right.$ meals/ $\left.{ }^{(17)}\right)$.

Like cattle, sheep also graze in cycles interrupted by rumination, rest and idling periods, with the majority of grazing occurring in daylight hours and little grazing in darkness. The patterns of grazing for cattle and sheep described by Hafez \& Schein ${ }^{(14)}$ and Hafez \& $\operatorname{Scott}^{(15)}$, respectively, are remarkably similar across the species, reflecting the diurnal nature of both species and probably an innate evolutionary programming to time feeding so as to limit the possibility of predation. 
Despite the consistent inter-species feeding habits, feeding patterns, and resultant VFI, can be greatly influenced by:

(i) feed allowance and type $e^{(18,19)}$ and consequent products of digestion $^{(20,21)}$;

(ii) imposed management regimen ${ }^{(16)}$;

(iii) day length and/or weather ${ }^{(14,22)}$.

(iv) genetics ${ }^{(5)}$;

(v) level of production ${ }^{(23)}$;

(vi) stage of the production cycle (for example, stage of lactation) and hence metabolic rate ${ }^{(14)}$;

(vii) interactions between these factors.

For instance, when grazing ruminant animals are supplemented with additional feeds, time spent grazing and herbage intake decline (substitution ${ }^{(19)}$ ), reducing the potential benefit from the supplement. However, for example, in the dairy cow, the extent of this decline is dependent on herbage availability, cow genetics ${ }^{(5)}$ and/or the milk production of the cow at the time of supplementation $^{(19)}$. A better understanding of the factors influencing VFI potentially offers the animal scientist an opportunity to better manage feed allocation, feed supply and animal breeding, and improve DM intake and whole-animal productivity. Van Soest ${ }^{(7)}$ identified two distinct factor classes controlling VFI:

(i) physical (feed) factors;

(ii) physiological (animal) factors.

\section{Physical factors regulating intake}

Although physical factors influence VFI, through reticulorumen and gastric distension and increased rumen retention time primarily, a thorough analysis of the subject is outside the scope of the present paper, and the reader is referred elsewhere for comprehensive reviews ${ }^{(9,10,24)}$.

The most likely physical factors affecting DM intake are dietary fibre content, the digestibility of that fibre, and the rate at which fibre is degraded in the rumen. Although dietary protein has been reported to have positive effects on DM intake ${ }^{(25)}$, this is probably a physiological or microbial response to additional nutrients and not a true physical factor. Chemical measures of fibre content are inversely associated with forage digestibility (Van Soest ${ }^{(7)}$; JR Roche, LR Turner, JM Lee, DC Edmeades, DJ Donaghy, KA Macdonald, JW Penno and DP Berry, unpublished results), in theory leading to increased rumen retention time, slower passage rate, and reduced VFI and DM intake with increases in forage fibre content. Despite this relationship, a strong association between dietary fibre content and DM intake in grazing ruminant animals has not been identified.

Mertens ${ }^{(26)}$ suggested that dietary fibre was the limiting factor in VFI in dairy cows otherwise well fed, and there is evidence that VFI in ruminant animals is limited by the inclusion of indigestible material that is too long to pass out of the rumen ${ }^{(27)}$. However, Allen ${ }^{(10)}$ noted considerable variation among experiments in the decline in VFI associated with increasing fibre, and suggested that the filling effect of fibre differs between diets. Consistent with this, Dado \& Allen ${ }^{(28)}$ reported a decline in VFI when additional inert bulk was added to the rumen of cows fed a diet containing $35 \%$ neutral-detergent fibre (NDF), but not a diet of $25 \%$ NDF. Subsequent work by Dado \& Allen $^{(29)}$ identified NDF digestibility as a contributor to the effect of NDF on VFI, with increased NDF digestibility positively associated with VFI. Further research is required to determine the point at which NDF limits VFI, and the interaction between feed NDF content and NDF digestibility.

Data indicate a multifaceted control of VFI in ruminant animals, combining the immediate physical constraint of a fibrous meal with the delayed physiological effects of products of digestion. This hypothesis is consistent with the immediate reduction in VFI with the presence of a physical constraint in the rumen and a delayed reduction in VFI following the inclusion of an energy-based supplement ${ }^{(30)}$. The present review will focus on the physiological factors influencing VFI.

\section{Physiological factors regulating intake}

Despite the importance of the physical nature of the diet, Seone et al. ${ }^{(31)}$ reported that VFI could still be influenced (increased in satiated sheep and suppressed in hungry sheep) in experiments where blood from satiated and hungry sheep was mixed in vivo. These data are consistent with the parabiotic model tested in rodents ${ }^{(32)}$ and reflect the presence of circulating factors as hunger signals and determinants of the point of satiety.

The central nervous system (CNS) undertakes the homeostatic role of sensing nutrient intake and body reserves, integrating the information, and regulating energy intake and/or energy expenditure. Short-term control of energy intake is mainly brought about by the integration of peripheral and central sensory pathways related to hunger and satiation, whilst long-term energy balance is accomplished through a highly integrated neuro-humoral system that minimises the impact of short-term fluctuations in energy balance on metabolic reserves. Critical elements of this control system are metabolites and hormones secreted in proportion to the animal's energy status and metabolic reserves, and the CNS targets upon which they act.

Recent discoveries of new metabolic signalling pathways along with renewed research efforts into understanding the control of hunger, satiety, and body weight with the soaring problem of human obesity, have resulted in rapid advances in our understanding of central control systems. The focus has now shifted to the identification of orexigenic (intakestimulating) and anorexigenic (intake-inhibiting) neurohormonal systems that respond to circulating signals and vary with overall metabolic state.

Metabolic state is reflected to the brain via a diverse array of signals, which can primarily be divided into orexigenic and anorexigenic signals. Peripheral signals that regulate VFI must accurately reflect both the long-term energy stores (i.e. adiposity, homeorhetic signals) and the concentrations of key nutrients, metabolites and hormones in circulation that indicate the immediate energy status of the body (i.e. homeostatic signals). Irrespective of animal species, if a hormone, neurotransmitter or other internal signal is to be classified as an orexigenic or anorexigenic signal, it must fulfil key criteria ${ }^{(13,33)}$ : 
(i) It must circulate in either direct or inverse proportion to the degree of adiposity, with concentrations modified reciprocally with changes in adipose stores.

(ii) It must gain access to the brain and interact with the receptors and transduction systems in neurons known to regulate energy balance.

(iii) Exogenous administration should affect VFI or meal size.

(iv) Blocking or compromising its endogenous activity should affect VFI or meal size.

(v) A reduction in VFI caused by administration of an 'anorexigenic' signal should not be the consequence of illness or malaise, or of some sort of incapacitation.

(vi) The secretion of endogenous orexigenic signals must follow a period of fasting. Similarly, the secretion of endogenous anorexigenic signals must be elicited by ingested food, with a temporal profile consistent with contributing to the normal cessation of eating.

(vii) Chronic infusions should alter body fat mass and the responsiveness of peripheral tissues to energy and adrenergic stimuli.

Although overly simplistic to reduce a behaviour as complex as feeding to a series of molecular interactions ${ }^{(34)}$, extensive research into the effect of hypothalamic lesions in the 1940s, 1950s and $1960 \mathrm{~s}^{(35-38)}$ and the discovery of numerous peptides has provided a greater understanding of factors produced in peripheral tissues that alter feeding behaviour. Over the last decade in particular, important advances have been made in the characterisation of hypothalamic neuronal networks and neuropeptide transmitters, along with the discovery of circulating peptides that send signals to the brain regarding the body's nutritional status $^{(39)}$. The major sources of these signalling molecules appear to be the adipose tissue, the gastrointestinal (GI) tract and the pancreas, although this does not preclude the existence of, as yet unidentified, VFI-regulating signals from muscle or bone tissue.

\section{Central mechanisms involved in nutrient sensing and intake regulation}

The neural network sensitive to energy status signals has been located to areas of the CNS stretching from the hypothalamus to the lower part of the brainstem. This has been identified as the homeostatic control centre for the regulation of VFI and energy balance.

Obesity has long been associated in some way with the hypothalamic-pituitary complex ${ }^{(40)}$. In fact, Brobeck ${ }^{(41)}$ attributed the first inference to this relationship in the clinical description of the association between a case of rapid weight gain and a tumour of this region. Classic neural lesion experiments in rats highlighted the predominant role of the hypothalamus in VFI control ${ }^{(35)}$. Bilateral lesions of the medial hypothalamus resulted in the exhibition of excessive orexigenic signals (hyperphagia) and obesity. Further studies suggested that VFI had multiple hypothalamic control centres ${ }^{(36)}$; medial hypothalamic electrostimulation inhibited VFI in rats, whereas stimulation of the lateral hypothalamus stimulated intake. This prompted Stellar ${ }^{(42)}$ to propose that the ventromedial region of the hypothalamus was the anorexigenic centre (inhibiting VFI) and the lateral hypothalamus was the orexigenic (feeding stimulation) centre.

Various hormones have been implicated in the short-term control of VFI, with many peptides increasing in circulation before evident satiation ${ }^{(43,44)}$, while ghrelin, in particular, increases before eating. However, most research into the effect of these signalling peptides in conveying the anorexigenic feeling to the CNS has been undertaken in single-stomached animals, and less is known about these signalling pathways in ruminant animals.

Anorexigenic signals directly influence VFI responses that are generated in the limbic system, and orexigenic signals are regulated by neurohormones, especially serotonin in the lateral hypothalamus ${ }^{(45)}$. However, the decision on whether to eat or not appears to be controlled by multiple factors, with the final decision relying on the 'total signal' reaching the CNS from many types of receptors in many parts of the body.

In addition to circulating signals of energy status, tension receptors in the muscular wall of the rumen and reticulum provide a measure of distension, while epithelial receptors provide information on the fibrousness of the digesta ${ }^{(46)}$. The epithelial receptors are also sensitive to the chemical nature of the digesta, particularly acidity. Furthermore, there are mechano- and chemoreceptors in the abomasum (true stomach) and duodenum, and chemoreceptors in the liver. Afferent fibres from nerves of the GI tract continuously receive information related to a number of mechanical and chemical stimuli. They transmit this (neural) information to the CNS to exert feedback control of both GI muscle contraction and intestinal secretions, and also participate in the regulation of VFI. In the rodent, the integration of GI neural information is mainly in the caudal nucleus of the solitary tract (NST) in the hindbrain ${ }^{(47,48)}$, although receptor binding studies have demonstrated that the area postrema in the hindbrain, as well as the caudal NST, contain high concentrations of binding sites for some peptides ${ }^{(49,50)}$. The area postrema and NST may be able to detect circulating peptides, raising the possibility that these hindbrain regions may be involved in VFI regulation by systemic factors as well as via neural pathways.

\section{Transport systems}

For a circulating signal to affect the feeding control centres of the CNS it must be able to gain access to the brain, which maintains a stable internal environment by protecting itself from fluctuating levels of peripheral molecules. Therefore, the transport of metabolic signals into the CNS must be considered when evaluating these pathways.

The capillaries in the brain are formed from a specialised endothelium whose function is to regulate the movement of solutes between blood and the brain (i.e. the blood-brain barrier; BBB). Studies of the $\mathrm{BBB}$ have revealed a limitation on the rate of exchange of lipid-insoluble substances, such as peptide hormones, between blood and nervous tissue ${ }^{(51)}$. The main significance of this limitation is that the power to control the composition of the cellular environment making up the nervous tissue is built into the system via carrier-mediated transport, or 'facilitated 
transport' of lipid-insoluble molecules ${ }^{(52)}$. Work by Stein et al. ${ }^{(53)}$ indicated that diffusion alone cannot explain the entry of insulin into the CSF, and this is consistent with the presence of a transport mechanism ${ }^{(53,54)}$.

Nutritional factors (for example, high concentrations of several of the unsaturated fatty acids ${ }^{(55,56)}$ ) modify BBB permeability. Strubbe et al. ${ }^{(57)}$ found that, whereas insulin readily appears in the CSF during an intravenous glucose infusion in free-feeding rats, $1 \mathrm{~d}$ fasting causes a significant decrease in the entry of insulin into the CSF after an intravenous glucose infusion. This suggests that the ease of insulin penetration, and perhaps other metabolic substances, into the CNS can be altered systematically under different metabolic conditions. Moreover, it is now believed that central resistance to leptin may arise in obese animals, which may be caused by a reduced ability of the BBB to transport leptin into the brain ${ }^{(58)}$. Consistent with this, it has recently been shown that the proportion of circulating leptin entering CSF is higher in thinner than fat sheep ${ }^{(59)}$.

\section{The arcuate nucleus of the hypothalamus}

A major site of VFI regulation is the hypothalamic arcuate nucleus (ARC), otherwise known as the infundibular nucleus. The ARC is an aggregation of neurons in the mediobasal hypothalamus, adjacent to the third ventricle and the median eminence. By monitoring the blood levels of metabolic substances, arcuate neurons are informed of whether or not the animal's body has sufficient energy and nutrients, so that it can adjust feeding behaviour accordingly.

The ARC contains two distinct neuronal populations that express leptin and insulin receptors ${ }^{(60,61)}$. One is a population that expresses pro-opio-melanocortin (POMC). POMC is a precursor peptide hormone that is further processed into multiple hormones, including the anorexigenic hormone $\alpha$-melanocyte-stimulating hormone. Leptin activates POMC-containing neurons resulting in the release of $\alpha$-melanocyte-stimulating hormone ${ }^{(61,62)}$. Leptin also interacts with the second ARC population to inhibit the release of the orexigenic neuropeptide Y (NPY) and agoutirelated protein $(\mathrm{AgRP})$ peptides ${ }^{(63,64)}$, thereby also removing the $\gamma$-aminobutyric acid inhibition of POMC neurons. The end result is that at times of energy excess and/or increased fat levels, increased leptin levels directly impede the activation of the orexigenic ARC pathways, and stimulate the anorexigenic-associated ARC pathways. Conversely, during times of energy deficit when leptin levels are low, there is a reduction in the inhibitory influences of leptin on orexigenic pathways. It is important to note that leptin is not the only key factor in the homeostatic control of VFI and energy balance; however, the common mode of action of leptin and the other factors appears to be related to an interaction with the NPY, AgRP and POMC neuronal targets.

The evidence for key roles for NPY and the melanocortins in the regulation of VFI and energy balance is increasing. Central injection of NPY stimulates VFI in animals, including ruminant species ${ }^{(65-68)}$. Hypothalamic NPY gene expression and circulating levels increase in response to feed restriction ${ }^{(69-71)}$ and decrease in response to feed excess ${ }^{(70-72)}$.
There is also evidence for the differential expression of orexigenic neurones, depending on the time frame of the feed restriction. For example, it has been reported in rodent and ruminant species that there are NPY-expressing cell bodies in the dorsomedial hypothalamus that do not possess leptin receptors ${ }^{(73,74)}$ and that NPY expression in these neurons is increased by the metabolic demands of lactation and chronic, but not acute, feed restriction ${ }^{(75-77)}$.

Although NPY-neuronal expression is without question a potent orexigenic stimulus, the absence of NPY or its receptors in rodent 'knock-out' models does not result in the cessation of feed intake ${ }^{(78,79)}$. This may just indicate that there are multiple systems for stimulating feed intake and the absence of one is not sufficient to block this critical behaviour. Melanocortins are the other arcuate peptides that play a major role in mediating the effects of circulating metabolic signals on VFI and energy balance. POMC mRNA expression and circulating $\alpha$-melanocytestimulating hormone levels are positively correlated with feed restriction in rats and sheep ${ }^{(80,81)}$, and, at least in mice, central administration of the POMC-derivative $\alpha$-melanocyte-stimulating hormone or melanocortin agonists inhibit $\mathrm{VFI}^{(82)}$.

Gene expression of POMC in the ARC is decreased during lactation in sheep ${ }^{(77)}$, facilitating the lactationassociated hyperphagia. In addition, the expression of the endogenous melanocortin antagonist, AgRP, which is colocalised with NPY in the ARC, is up-regulated during feed restriction $^{(70)}$ and lactation ${ }^{(77)}$ in sheep, and central administration of AgRP increases VFI in mice ${ }^{(82)}$. Arcuate NPY/AgRP and POMC-containing neurons have primary projections to both the paraventricular nucleus and to the lateral hypothalamus ${ }^{(61,83)}$, both areas known to be involved in homeostatic (intake) regulation.

In addition, the paraventricular nucleus and lateral hypothalamus have projections to the dorsal-vagal complex of the hindbrain ${ }^{(84,85)}$, which receives neural input from the GI tract. Therefore, there is probably cross-talk between CNS control centres receiving inputs from neural and circulating signals.

In conclusion, the animal's body possesses multiple central pathways for the homeostatic regulation of VFI and energy balance, and there is sufficient information to believe that data that have been collected on single-stomached species are equally relevant to ruminant livestock. Whilst there are differences in the location of the integration of short- and long-term feedback signalling within the CNS, and even with the mode of signalling, there appears to be overlap and cross-talk between these pathways. With increased knowledge of the exact nature of the integration centres, and the signals to which they respond, the sequence of events leading to anorexigenic or orexigenic signals will be better understood, and manipulation of these through either genetic selection or animal management will be possible.

\section{Peripheral mechanisms involved in intake regulation}

Although it is the CNS that regulates energy homeostasis, it is responding to signals produced peripherally in proportion to the status of adipose tissue reserves, and in response to the provision and ingestion of food, and the products of 
digestion (i.e. rumen fermentation and intestinal digestion; Fig. 1). The existence of a humoral factor circulating in blood and controlling feeding behaviour is consistent with the lipostatic theory and has been extensively studied in the parabiotic rodent model ${ }^{(32)}$. Support for this model also acting in ruminant animals was provided by Seoane et al. ${ }^{(31)}$ in sheep. Blood from the jugular veins of hungry and satiated sheep was exchanged and feed consumption by satiated sheep increased $48 \%$ over control values while feed consumption by hungry sheep decreased $17 \%$. These results provide evidence of humoral factor(s) regulating feeding behaviour being present in the blood of farm ruminant animals. Gaining an understanding of the physiological systems regulating VFI is fundamental to improving the productivity of ruminant livestock.

\section{Adipose tissue and long-term intake regulation}

The importance of the fat depot in the regulation of VFI was hypothesised by very early physiologists such as Darwin ${ }^{(86)}$ and Bernard ${ }^{(87)}$. One of the most important theories in this field was proposed by Kennedy ${ }^{(40)}$, that the effect of the hypothalamus in anorexigenic or orexigenic signals is primarily 'lipostatic' or 'adipostatic', suggesting that genetic and environmental factors dictate an individualised level of body adiposity, which animals strive to maintain. Deviations from the defended level of adiposity trigger compensatory changes in appetite and energy expenditure that persist until the level of body fat is restored ${ }^{(3)}$.

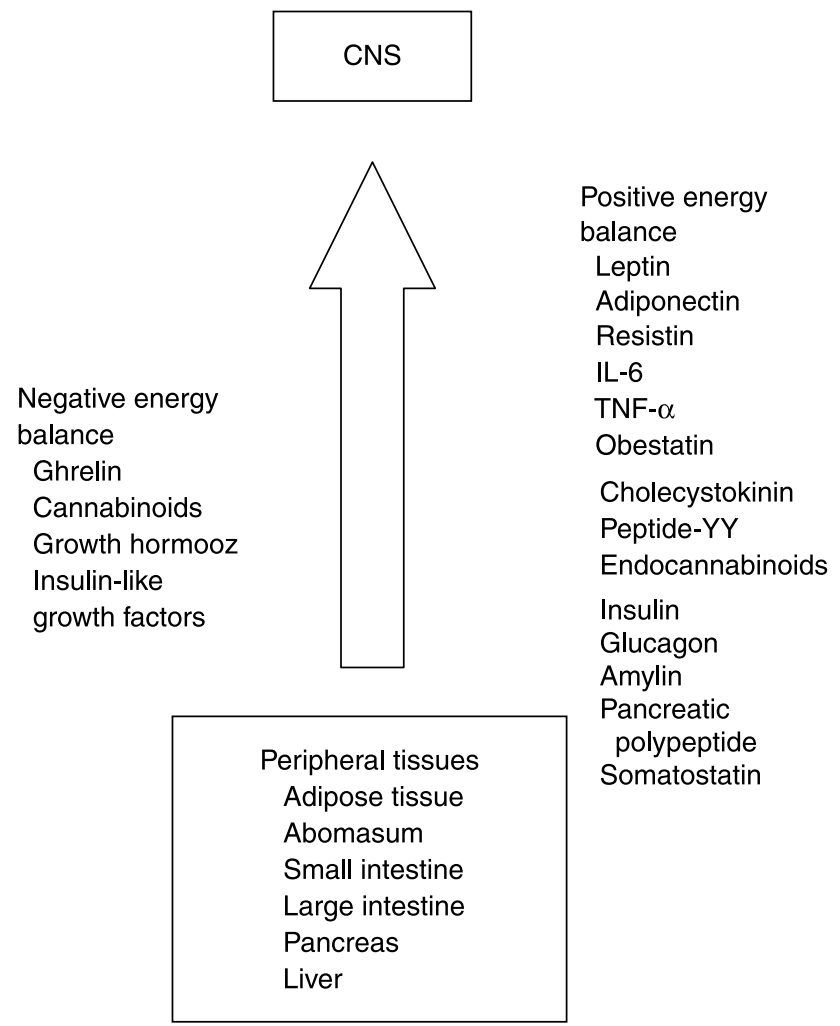

Fig. 1. A schematic representation of the interaction between energy balance and peripheral signalling to the central nervous system (CNS).
Kennedy ${ }^{(40)}$ noted that the size of body stores remained relatively constant in adult animals allowed to eat balanced diets without interference. He deduced that animals appeared to regulate their stored reserves. A number of studies have since confirmed the validity of this hypothesis, with animals on restricted allowances increasing their intake beyond that of the control comparison, when given unrestricted access to feed, until such time as their body weight returned to the weight of the control cohort $^{(88,89)}$. These results point to a VFI-regulating effect of adipose tissue.

Although more difficult to test the lipostatic hypothesis on larger mammals, it has been postulated that there is a certain minimum body fat content below which the lactating cow will not venture willingly ${ }^{(90)}$, suggesting that the hypothesis may also be valid in larger mammals. However, until recently little direct evidence existed to either support or refute the theory in domesticated ruminant species. Roche et al. ${ }^{(91)}$ highlighted a linear decrease in the amount of weight lost in early lactation with decreasing adiposity at calving, and Holter et al. ${ }^{(92)}$, using calorimeters, reported that thinner cows at calving exhibited a lower negative energy balance post-partum by modifying energy expenditure to reduce weight loss.

Further proof of the innate desire for animals to maintain a certain level of adiposity was presented by Roche et $_{\text {al. }}{ }^{(91)}$. They noted that a 2.5 unit difference in calving body condition score (BCS; ten-point scale) declined to less than a one-unit difference $250 \mathrm{~d}$ post-calving, indicating that dairy cows modify either energy intake or expenditure (milk production) or both, in an attempt to maintain a constant fat store appropriate for their physiological state. More direct evidence of this was reported by Tolkamp et al. ${ }^{(93)}$, who demonstrated a negative effect of body fatness on VFI in sheep. Similarly, McCann et al. ${ }^{\left({ }^{(9)}\right.}$ and Caldeira et al. ${ }^{\left({ }^{95}\right)}$ reported a rapid rise in VFI in lean sheep fed ad libitum until a BCS of 3.7-4 (on a five-point scale) was obtained, at which point VFI declined rapidly to a constant lower level such that body weights were maintained.

Further proof of the validity of the lipostatic theory in ruminant animals was presented by Broster \& Broster ${ }^{(96)}$, who reported that VFI per litre milk decreased by $1.3 \mathrm{~kg} / \mathrm{d}$ for every unit increase in BCS (five-point scale) at calving, highlighting a physiological willingness to use stored reserves for production with increasing adiposity. These data are in agreement with the positive effect of calving BCS on milk yield/cow in early lactation $^{(97)}$, although data indicate a threshold above which an increase in adiposity has a negative effect on milk production.

The existence of adaptive alterations in VFI to changes in body-fat stores indicates the existence of 'adiposity signals' that communicate the status of fat stores to the brain ${ }^{(33)}$. Amazingly, such adiposity signals were only discovered some 40 years after Kennedy ${ }^{(40)}$ proposed his lipostatic theory. Initially the hormone leptin was identified ${ }^{(98)}$, with further hormones produced by the adipocytes discovered subsequently. Those hormones have transformed our understanding of the role of the adipose tissue from that of a simple energy-storage organ to that of both an energystorage and an endocrine organ ${ }^{(99)}$. 
Ruminant species, like most mammals, have different types of adipose tissues (brown or white) and different depot stores (subcutaneous, intramuscular, and abdominal) ${ }^{(100)}$. Brown adipose is predominantly found in young mammals and has an important role in the perinatal thermogenesis ${ }^{(101)}$. The study of the contribution of signals produced by adipose tissues to the regulation of VFI has mainly focused on signals coming from white adipose tissue depots, and the distinction between depot location has not been studied extensively.

Over the last 15 years, adipose tissue has become recognised as a true and complex endocrine organ. Amongst the large number of recognised hormones produced by the adipocytes, leptin appears to be the main regulatory signal of VFI. However, it is probable that the adipose tissue might have an integrative role in the regulation of VFI, because leptin expression and secretion are regulated by external environmental factors, a number of other hormonal systems, themselves sensitive to metabolic status, and adrenergic inputs $(102-104)$.

Leptin. Leptin (from the Greek leptos, meaning thin) is a $16 \mathrm{kDa}$ polypeptide product of the $o b$ (obese) gene ${ }^{(98)}$. The gene for leptin has been sequenced for cattle and sheep, and differs by only two conservative amino acids ${ }^{(105)}$.

Leptin is produced by adipose tissue primarily, but also by the placenta, the skeletal muscle, the mammary tissue, and within the brain. In all ruminant animals, plasma concentrations are correlated with the amount of fat mass in animals that are not under any energetic or thermal stress, or stress of any other nature ${ }^{(105-108)}$.

Leptin plays a key role in regulating energy intake and energy expenditure, including the orexigenic-anorexigenic complex and metabolism. Its role in the control of energy balance was first reported in the ob/ob mouse, a phenotype that presents hyperphagia, impaired thermogenesis, obesity and abnormal neuroendocrine profiles ${ }^{(109)}$. In this model of obesity, peripheral (intraperitoneal or intravenous) or intracerebroventricular (icv) administration of leptin reduced VFI and activated $\mathrm{BMR}^{(110)}$. Furthermore, administration of endogenous leptin prevented the normal endocrine response to fasting, such as the reduction in the activity of neuroendocrine systems such as the thyroid, reproductive and growth axes, and the activation of the hypothalamicpituitary axis (for a review, see Ahima et al. ${ }^{(111)}$ ).

Leptin interacts with six types of receptor (LepRaLepRf), although LepRb is the only receptor isoform that contains active intracellular signalling domains. This receptor is present in a number of hypothalamic nuclei. Leptin is transported across the BBB by a short form of the leptin receptor ${ }^{(112)}$. Once in the brain, leptin binds to a long form of its receptor - a membrane receptor - present in high concentrations in specific neurons located in the $\mathrm{ARC}^{(113-117)}$. The mRNA encoding for the ob receptor are mainly expressed in a population of orexinergic neurons coexpressing NPY and AgRP mRNA and in separate populations of anorexinergic neurons co-expressing cocaineand amphetamine-regulated transcript and POMC ${ }^{(113-118)}$ Leptin reduces VFI by stimulating the activity of the anorexinergic neurons and by decreasing the activity of the orexinergic neurons (for a review, see Ahima ${ }^{(118)}$ ).
In addition, leptin inhibits other orexinergic peptides, such as melanin-concentrating hormone and orexins, which are expressed in the lateral hypothalamic area of rodents and sheep $^{(118-120)}$. Outside of the diencephalon, leptin also act on neurons of the NST, dorsal motor nucleus of the vagus nerve, lateral parabrachial nucleus, and central grey of the brainstem $^{(121)}$. In the obese rodent, the action of leptin in the brainstem seems to be part of the mechanisms involved in short-term adjustments of energy intake such as regulation of meal size by cholecystokinin $(\mathrm{CCK})^{(122)}$

In ruminant species, the literature on leptin has been dominated by studies on the role of leptin (and fat reserves) in the control of reproduction. However, some of these studies have also demonstrated an effect of leptin in regulating VFI; the effects, however, are ambiguous. Physiologically large amounts of leptin (more than $0.04 \mu \mathrm{g} / \mathrm{h}$ infused intracerebrally) have been reported to decrease VFI (by up to $70 \%$ within $5 \mathrm{~d}^{(123)}$ ), but this anorexic effect is not universal. There are indications of seasonal dependency, with intacerebral injections of $1.5 \mathrm{mg}$ leptin inducing a $30 \%$ decrease in DM intake in sheep in autumn, but not in spring ${ }^{(124)}$, reflecting a possible interaction of leptin with photoperiod ${ }^{(125)}$. Consistent with these data, recent evidence also suggests that the hypothalamic orexigenic-anorexigenic regulatory mechanisms are less sensitive to leptin in sheep during spring than autumn, possibly due to a shift in leptin receptor sensitivity. Changes in photoperiod may inhibit leptin brain entry at the $\mathrm{BBB}$ in spring to prevent its anorectic actions when appetite and energy balance are at a seasonal low ${ }^{(59)}$.

In contrast, the seasonal effect of leptin on VFI was reversed in castrated sheep, with no effect in autumn but a decrease in spring ${ }^{(126)}$. In the same experiment Clarke et al. (126) also demonstrated that VFI is less sensitive to leptin in male than female sheep (25 v. $75 \%$ reduction of DM intake in response to intracerebral infusion of leptin); these results indicate a possible interaction between photoperiod, the sex steroids and leptin in the regulation of VFI. Other hormonal mechanisms known to be influenced by photoperiod and also to have a direct effect on VFI, such as melatonin or prolactin ${ }^{(22)}$, could also interact with leptin in the control of $\mathrm{VFI}^{(127)}$

In addition to its chronic regulatory effect, leptin also appears to have an effect in the short-term regulation of VFI. Plasma concentrations of leptin decrease within hours of fasting and increase within hours following an increase in intake (for reviews, see Zieba et al. ${ }^{(104)}$ and Adam et al. ${ }^{(125)}$ ). Similarly, plasma leptin concentrations decrease after an abrupt reduction in intake or following an energy challenge, such as the start of lactation ${ }^{(108,128)}$. The evident changes in plasma leptin concentrations over a time frame too short to affect level of body fatness raise a few questions about factors controlling its production. It has been demonstrated that level of intake can affect the expression of mRNA encoding for the long form of the leptin receptor in sheep and cattle ${ }^{(113)}$, suggesting that this variation in sensitivity to leptin could be part of the mechanism of action of leptin on $\mathrm{VFI}^{(125)}$. Regulation of leptin secretion by acute changes in energy balance ${ }^{(129,130)}$ reflects an adipocyte response to circulating hormones or metabolites that are affected by energy intake and known to regulate leptin secretion, such as insulin ${ }^{(131)}$, 
and not changes in adipose stores per se. This rapid response in circulating leptin concentrations to changes in VFI or energy expenditure supports a role for leptin in maintaining adiposity, and could possibly explain some of the daily fluctuation in VFI observed in animals fed ad libitum on an average-quality ration ${ }^{(93)}$.

Other signals from adipose tissue. Adiponectin, a $30 \mathrm{kDa}$ polypeptide secreted primarily by the white and brown adipose tissue ${ }^{(132,133)}$, has no apparent direct effect on VFI in laboratory animals; however, plasma concentrations are inversely correlated with fat mass in humans and rodents $^{(132)}$. There are two adiponectin receptors; AdipoR1 is mainly expressed in skeletal muscle, and AdipoR2 in the liver. However, an adiponectin receptor has, as yet, not been identified centrally ${ }^{(134)}$, making it unlikely that adiponectin has a direct effect on central pathways regulating VFI. Furthermore, peripheral administration of adiponectin in rodents stimulates energy expenditure and reduces bodyweight gain, without any apparent change in VFI (for a review, see Kadowaki \& Yamauchi ${ }^{(134)}$ ).

Adiponectin may instead play an indirect role in VFI regulation. Plasma concentrations of adiponectin are inversely correlated with the degree of insulin resistance ${ }^{(134)}$, and adiponectin administration improves glucose uptake by peripheral tissues in rodents ${ }^{(135)}$. This adiponectin-mediated effect on insulin resistance and glucose metabolism indicates a possible role for this hormone in the regulation of VFI, through changes in circulating glucose and insulin ${ }^{(136)}$.

Resistin is a $12 \mathrm{kDa}$ polypeptide produced primarily in white adipose tissue, although brown adipose tissue is also a source ${ }^{(133,137)}$. Resistin mRNA has been isolated in the ARC and ventromedial nuclei of the hypothalamus, indicating a possible role in the regulation of $\mathrm{VFI}^{(138)}$. Expression of resistin mRNA in adipose tissue is positively associated with feeding ${ }^{(137,139)}$, increasing following a meal, while circulating concentrations of resistin decrease with declining body weight ${ }^{(140)}$. These data indicate a likely satiation role for resistin. Consistent with this, central administration of resistin in the ARC of rats induces a rapid, transient, $50 \%$ decrease in VFI in fasted animals, and a $15 \%$ decrease in satiated animals within $2 \mathrm{~h}$ of administration. There was no effect of resistin on body weight, or plasma concentrations of leptin or adiponectin with this negative effect on $\mathrm{VFI}^{(138)}$, consistent with a direct central effect on VFI.

Resistin has additional physiological roles that may also associate it with VFI regulation. Mice infused with resistin exhibit impaired glucose homeostasis and insulin action $^{(137,141)}$. Further evidence of resistin's involvement in energy homeostasis is in the positive and negative effects of hyperglycaemia and hyperinsulinaemia, respectively, on resistin mRNA expression ${ }^{(142)}$. It is likely that resistin plays a similar role in ruminant animals because the expression of the resistin gene in adipose tissue is greater in lactating cows, when insulin concentrations are low and insulin resistance is high, than non-lactating cows ${ }^{(143)}$. Further research is required to determine whether resistin is a factor contributing to insulin resistance, or whether the insulin resistance in early lactation to facilitate use of tissue stores for milk production results in reduced resistin mRNA expression.
There are two cytokines secreted by adipose tissue that have been implicated in VFI regulation, IL-6 and TNF- $\alpha$. Despite their size, these cytokines gain access to the hypothalamus via active transport systems ${ }^{(144)}$. IL-6 circulates in multiple forms with a size between 22 and $27 \mathrm{kDa}$, and the receptor for IL-6 is also expressed in adipose tissue. There are IL- 6 receptors in the neurons of the ventral and dorsal nucleus of the hypothalamus of rats ${ }^{(145)}$.

In humans, concentrations of IL-6 in the CSF are negatively correlated with fat mass and leptin concentration in the $\mathrm{CSF}^{(146)}$, and an injection of IL-6 can reverse the obesity observed in IL-6 knock-out mice ${ }^{(147)}$. Moreover, central injection of IL-6 decreased VFI and increased energy expenditure ${ }^{(148)}$ in rats, indicating an anorexigenic and lipolytic function in energy metabolism. However, there are no data available on the effect of IL-6 on VFI in ruminant animals.

TNF- $\alpha$ is expressed in ovine and bovine adipose tissue ${ }^{(149,150)}$, and plasma concentrations increase with level of fatness ${ }^{(149)}$. Peripheral administration has been shown to reduce VFI in rodents ${ }^{(144)}$. As well as transport systems that facilitate $\mathrm{TNF}-\alpha$ crossing the $\mathrm{BBB}$ and influencing VFI directly, peripheral TNF- $\alpha$ also causes the secretion of leptin, possibly suppressing VFI indirectly ${ }^{(144)}$. Consistent with this, administration of leptin antisera reversed the anorexic effects of lipopolysaccharide infusion $^{(151)}$. However, there are no data available on the effect of TNF- $\alpha$ on VFI in ruminant animals.

\section{The gastrointestinal tract}

Since the discovery in 1902 that the pancreas secreted a hormone in response to intestinal acidification ${ }^{(152)}$, and the hypothesis that this hormone (secretin) was a peptide or protein, many other peptides have been discovered as regulators of intestinal function. In particular, the GI tract is recognised as the source of a number of factors believed to stimulate either meal initiation or cessation in response to the presence of food in the stomach and lumen of the GI tract, and/or nutrients, metabolites and hormones circulating in blood. These factors play a very important role in the acute regulation of VFI, as they are required to provide feedback to the brain on the size and energy/nutrient content of a meal before digestion has occurred and the nutrients have entered the blood.

There is a greater amount known about factors regulating the termination of meals than the stimulation thereof; until recently it was postulated that there was a constant background orexigenic stimulus, which was modulated by the production of anorexic agents ${ }^{(13)}$. The discovery of ghrelin ${ }^{(153)}$, a potent orexigenic agent produced primarily in the oxyntic cells of the stomach (and abomasum in ruminant animals), the production of which declines post-feeding $^{(154-156)}$, and the infusion of which either peripherally or centrally causes a rapid transient increase in VFI in rodents ${ }^{(157)}$, human subjects ${ }^{(158)}$ and ruminant species $^{(159,160)}$, has undermined this hypothesis somewhat and provided evidence for a peripheral meal initiation signal.

Ruminal fermentation products and the subsequent substrates for intestinal digestion interact with receptors lining the stomach and intestine, causing the release of 
peptides and other factors that coordinate the digestion of the particular food being consumed ${ }^{(13)}$. Some of these factors signal the brain and other areas of the CNS, providing information on both the quantity and type of food being ingested. The secretion of orexigenic agents is reduced following eating, while anorexic signalling increases when food enters the lumen of the digestive tract. As the integrated signal accumulates it creates a feeling of fullness (anorexigenic) and contributes to the cessation of eating ${ }^{(13)}$.

Regulatory factors produced in GI tract include CCK, peptide $\mathrm{YY}_{3-36}(\mathrm{PYY})^{(161)}$, ghrelin ${ }^{(162)}$, obestatin $^{(163)}$ and gastrin-releasing peptide ${ }^{(164)}$. Woods ${ }^{(13)}$ pointed to the necessity of having more than one anorexigenic mechanism, allowing the subject to eat whatever food is available, secrete a cocktail of peptides appropriate for digesting the particular food eaten, but still informing the brain as to precisely what has been eaten. Although this requirement may not be as necessary in ruminant animals as it is in single-stomached subjects, because of the fermentation that occurs in the rumen, proteins, fats, fibre and some carbohydrates do progress post-ruminally, and it is important that there are mechanisms in place to inform the brain and CNS of their imminent digestion. In addition to this, there is an additional requirement in ruminant animals that the volatile fatty acids (VFA) produced in, and absorbed into circulation from, the rumen are recognised and a detailed account relayed to the brain.

Vagus nerve. The afferent fibres of the vagus nerve are the major neuro-anatomic linkage between the alimentary tract and the hindbrain. Afferent input related to anorexigenic signals, from the GI tract, the liver and from secreted metabolites, monoamines and peptides are transmitted through the vagus nerve and sympathetic fibres to the NST in the hindbrain, where they integrate with descending hypothalamic input to produce ascending output regarding VFI to the hypothalamus ${ }^{(34,165)}$.

Vagal afferent fibres supplying the upper GI tract are sensitive to three classes of meal-related stimuli: mechanical distension of the lumen or gut contraction, chemical properties of luminal contents, and gut peptides and neurotransmitters, whose secretions have been elicited by the presence of meals in the duodenum. Schwartz et al. (166) demonstrated that combinations of gastric load and exogenous peptides excited gastric vagal mechanoreceptors to a greater degree than either stimulus alone. These data indicate that individual gut vagal afferents possess distinct transduction mechanisms for the different classes of mealrelated negative feedback signals, and can simultaneously integrate these signals to send a coherent message regarding meal size to the intake-regulation centre in the brain.

In addition to stimulation by peptides, single vagal afferents from the ileum and jejunum are excited by lipids, especially linoleic and oleic acids, indicating a role for gut vagal afferents in the anorexigenic signal and VFI reductions elicited by lipids.

Cholecystokinin. CCK is the archetypal GI anorexigenic signal and is one of the oldest peptides identified as having an effect on VFI. First reported to elicit an anorexigenic effect in gastric-fistulated rats in the early $1970 \mathrm{~s}^{(167)}$, it is found in the brain ${ }^{(168)}$, acting as a neurotransmitter, and in the GI tract ${ }^{(169)}$ in both secretory and neural tissue.

Although found widely along the GI tract, CCK is expressed in particular by enteroendocrine I cells in the duodenal and jejunal mucosa ${ }^{(39,170,171)}$. The triangular shape of the I cell, with the apical microvilli immersed in the food-containing contents of the lumen ${ }^{(172)}$ and the CCK secretory granules positioned at the base of the cell away from the lumen, as well as its distribution in the proximal GI tract, allow the cells to be stimulated by GI contents immediately following release from the stomach, and secrete CCK either into blood, in an endocrine fashion, or in a paracrine manner into surrounding tissue ${ }^{(170)}$.

CCK is found in multiple forms ${ }^{(173)}$, but all are derived from a single gene by post-translational or extracellular processing ${ }^{(170)}$. Preprocholecystokinin is a 115 -amino acid polypeptide that succumbs to cleavage to first form proCCK and subsequently CCK-58, the most processed form of CCK in most tissues ${ }^{(174)}$. All of the shorter forms of CCK are formed by monobasic or dibasic residues, and many of these smaller forms are found, together with CCK-58, in various tissues and in blood ${ }^{(175)}$.

CCK exerts a number of biological actions within the GI tract and beyond. Its release from the intestine is stimulated by the presence of digestive products in the GI lumen. Levels rise immediately, peaking within 30 min in cows ${ }^{(176)}$, and can remain elevated for $3-5$ h post-feeding ${ }^{(170)}$. Dietary fat and protein appear to be the most potent stimulators of CCK release in single-stomached animals, although the abomasal infusion of a starch hydrolysate in steers increased the plasma concentration of $\mathrm{CCK}$ while the infusion of casein tended to reduce blood concentrations of the peptide $^{(177)}$. Physiologically relevant concentrations of CCK have been implicated in reduced gastric emptying, stimulation of gallbladder contractions ${ }^{(178)}$ and the postprandial delivery of bile to the duodenum, pancreatic secretions, and stimulation of the vagus nerve. The presence of CCK receptors in the gall bladder of the $\operatorname{cow}^{(179)}$ indicates similar digestive effects of CCK in ruminant animals to those noted in single-stomached species.

In addition to its importance in the digestion of food, $\mathrm{CCK}$ has also been identified as an important anorexigenic peptide. Fulfilling all of the requirements of an anorexigenic stimulus, CCK rises with the presence of nutrients in the lumen of the GI tract and the pattern of feeding behaviour is altered by exogenous administration of physiologically relevant doses. CCK has now been shown to inhibit VFI across many species. When Gibbs et al. ${ }^{(167)}$ injected rats peripherally with CCK before a meal, meal size and duration were reduced. In addition, exogenous CCK administration to unfed rats resulted in behaviours characteristic of satiation ${ }^{(180)}$. The latter experiment highlights that the satiation actions of CCK are not only a result of delayed gastric emptying and subsequent gastric mechanoreceptor stimulation, although Moran \& McHugh $^{(181)}$ provided evidence that this is one VFIregulation mode of action of $\mathrm{CCK}$.

CCK peptides bind with two receptors, CCK1R and CCK2R (formerly known as $\mathrm{CCK}_{\mathrm{A}}$ and $\mathrm{CCK}_{\mathrm{B}}$, respectively). Both receptors are members of the seven 
transmembrane $\mathrm{G}$ protein-coupled receptor family ${ }^{(170)}$ and the relative distribution of these receptors varies across species. CCK1R is found in the GI tract, the peripheral nervous system, and the brain, whilst CCK2R is primarily found in the brain ${ }^{(170)}$.

CCK secreted by the proximal GI tract is proposed to work in a paracrine fashion, stimulating CCK1R receptors on the sensory fibres of the vagus nerve, thereby activating neurons in the NST in the hindbrain ${ }^{(170,182)}$. The signal initiates local reflexes and is relayed to the forebrain. This pathway is consistent with the reduction in the anorexigenic effects of CCK when the majority of the medial and commissural subnuclei of the NST as well as the area postrema are lesioned ${ }^{(183)}$, supporting the role of gastric afferent projections in the mediation of CCK-induced anorexigenic signals.

The distribution and biological activity of CCK has also been studied in ruminant species. Choi et al. ${ }^{(176)}$ reported that CCK mediates the depression in VFI in dairy cattle fed high-fat diets. Consistent with this effect, Simon-Assmann et al. ${ }^{(184)}$ reported that the distribution and biological activity of CCK is similar in rat and cow brains, suggesting similar effects of the peptide across the species. Farningham et al. ${ }^{(185)}$ examined the effect of propionate and CCK on VFI. Individual infusions of either CCK or propionate did not affect VFI, but a simultaneous infusion of CCK and propionate decreased VFI by $40 \%$. These data possibly implicate CCK in the termination of meals in ruminant livestock, but suggest an interaction with metabolites and nutrients of digestive processes.

Ghrelin. Ghrelin is a twenty-eight-amino acid (twentyseven in the bovine) peptide produced predominantly in the oxyntic cells of the stomach (abomasum in ruminant animals). It was originally identified as the endogenous ligand for the growth hormone $(\mathrm{GH})$ secretagogue receptor $(\mathrm{GHS}-\mathrm{R})^{(155)}$, mediating the release of pituitary $\mathrm{GH}$ through an alternative to the classical mechanisms of $\mathrm{GH}$ release mediated by the GH-releasing factor $(\mathrm{GRF})^{(186)}$. However, it quickly became evident that this hormone also has robust effects on VFI and metabolism ${ }^{(164,157)}$.

Extensive research since its discovery has identified the orexigenic effects of ghrelin in single-stomached animals ${ }^{(157,158,187)}$, and more recently Wertz-Lutz et al. ${ }^{(159)}$ and Harrison et al. ${ }^{(160)}$ reported similar effects in sheep and cattle. Central and peripheral infusion of ghrelin stimulates NPY and AgRP neurons in the hypothalamus ${ }^{(188,189)}$, and immunohistochemical analyses indicate that ghrelin neuron fibres are in direct contact with NPY and AgRP neurons ${ }^{(190,191)}$. These data indicate that ghrelin increases the sensation of orexigenic feelings, and presumably VFI, by stimulating NPY and AgRP neurons in the hypothalamus to secrete the orexigenic NPY and AgRP peptides, respectively ${ }^{(191)}$.

Ghrelin secretion is pulsatile ${ }^{(192)}$. In sated rats, ghrelin secretory episodes consist of low-amplitude pulses discharged at a regular frequency of two episodes per $h^{(193)}$. However, an apparent orexigenic drive, elicited by the negative energy balance following food deprivation, coincides with high-amplitude pulses at about three episodes per $\mathrm{h}^{(193)}$. Thus, when energy intake and expenditure are balanced, ghrelin secretion appears to be restrained ${ }^{(193)}$, but reduced energy resources rapidly curb this restraint to allow increased episodic ghrelin discharge ${ }^{(192)}$.

There are two forms of circulating ghrelin; an active (acylated) and inactive (des-acylated) form. Acylation of ghrelin is necessary for ghrelin to bind to the GHS-R and to cross the $\mathrm{BBB}^{(194)}$, while the inactive (des-acylated) form of ghrelin is activated by the addition of an octanoyl group (eight-carbon fatty acid) to the serine residue at position three.

Synthesis and secretion of ghrelin appear to be regulated by nutritional state. Circulating ghrelin concentrations decrease postprandially in both single-stomached ${ }^{(157)}$ and ruminant animals ${ }^{(154-156,195)}$. Consistent with its role as an endocrine and not distension-mediated peptide, plasma ghrelin declines rapidly following the gastric infusion of glucose or fat, but not water ${ }^{(196)}$, and following the intravenous infusion of glucose in human subjects ${ }^{(197)}$, rodents $^{(198)}$ and ruminant animals ${ }^{(199)}$. Overduin et al. ${ }^{(196)}$ also reported an effect of feed type, with isoenergetic intestinal infusions of either glucose or amino acids suppressing ghrelin concentrations more rapidly and effectively than lipid infusions. Further evidence that the effect of ghrelin is not distension-mediated is that gastric glucose infusion, while blocking the pyloric exit from the stomch, did not affect plasma ghrelin levels ${ }^{(200)}$.

Initial epidemiological studies in ruminant animals indicated a similar role for ghrelin in VFI regulation as was identified in single-stomached species. Roche et al. ${ }^{(156)}$ reported a postprandial decline in VFI, a positive correlation between genetic selection for production and plasma ghrelin concentration, and for the first time provided a neuroendocrine basis for substitution rate in grazing ruminant animals (i.e. the phenomenon by which animals reduce their time spent grazing when fed a supplement; $12 \mathrm{~min} / \mathrm{kg}$ supplement $\left.{ }^{(19)}\right)$. Consistent with these data, Sugino et al. ${ }^{(154)}$ also reported the pre- and postprandial trends in ghrelin concentration in sheep, and identified effects of feeding regimen on the intensity of the ghrelin pulses; preprandial ghrelin pulses were greater in sheep fed twice daily than those fed four times daily, possibly reflecting a greater orexigenic sensation in animals fed less frequently. They also reported a temporal increase in plasma GH concentrations followed a single pulse in plasma ghrelin, suggesting that the increase in ghrelin stimulated the $\mathrm{GH}$ surge during feeding.

Studies where ghrelin was infused into ruminant animals are few and the results are inconsistent. Iqbal et al. (201) reported no effect of ghrelin, infused either intravenously or intraperitoneally, on VFI in sheep. However, Harrison et al. ${ }^{(160)}$ reported an interaction of ghrelin with photoperiod, with a two-fold increase in VFI for the hour post-ghrelin infusion on long-day photoperiod, but not shortday. In comparison, Wertz-Lutz et al. ${ }^{(159)}$ demonstrated an increase in VFI in beef cattle during the hour following a subcutaneous ghrelin infusion, but Roche et al. ${ }^{(199)}$ reported no effect of continuously infused ghrelin on VFI in early lactation dairy cows. Further research is required to understand the effect of ghrelin on VFI in ruminant species, and the factors modifying that effect.

Ghrelin might also affect VFI indirectly via an effect on body tissue stores. Theander-Carrillo et al. ${ }^{(202)}$ 
demonstrated that a central ghrelin infusion independently regulated adipocyte metabolism in rats, partitioning more nutrients toward fat storage by increasing lipogenesis and inhibiting lipid oxidation in white adipocytes. Interestingly though, when the same amount of ghrelin was administered peripherally, none of the central ghrelin affects was seen $^{(202)}$. These results indicate that central ghrelin may 'prime' tissue to store energy as fat by altering adipocyte enzyme expression, and the authors have speculated that pre-feeding ghrelin peaks may be triggering meal preparation processes in the $\mathrm{CNS}$, rather than actually initiating meals. Tissue-specific changes were also seen with changes in mitochondrial and lipid metabolism gene expression favouring TAG deposition in the liver over skeletal muscle (203), suggesting that ghrelin could be involved in adaptive changes of lipid distribution and metabolism in the presence of energy restriction and loss of body fat ${ }^{(203)}$. In comparison, Roche et al. ${ }^{(199)}$ continuously infused ghrelin subcutaneously for 8 weeks in lactating dairy cows and found increased BCS loss and plasma NEFA concentrations, and lower leptin concentrations, suggesting that the effect of ghrelin on adipocyte function may differ in dairy cows, particularly in early lactation when the mobilisation of body reserves is extensive.

The factors regulating ghrelin secretion remain unclear. Although ghrelin concentrations drop rapidly in response to glucose infusion ${ }^{(197,199)}$, clamp studies in rodents have indicated that neither glucose nor insulin elicits the decline $^{(20)}$. Data from dairy cows ${ }^{(199)}$ identify a rapid drop in plasma ghrelin concentrations following glucose infusion, but the data could not discount a role of insulin in this process. Kalra et al. ${ }^{(193)}$ propose that leptin was the factor that inhibited gastric secretion of ghrelin and the stimulation of feeding by ghrelin. Rhythmic fluctuations in circulating concentrations of leptin have been observed in response to shifts in energy balance ${ }^{(192)}$. When comparing pulse amplitude between ghrelin and leptin during energy deprivation, ghrelin is markedly increased whereas energy deprivation diminishes leptin pulse amplitude, thereby diminishing overall leptin output ${ }^{(192)}$. This reciprocal relationship is seen both pre- and post-feeding, with lower circulating levels of leptin corresponding to greater circulating concentrations of ghrelin pre-feeding, and a gradual rise in postprandial leptin secretion preceding the decline in ghrelin secretion ${ }^{(205,206)}$.

Obestatin. Obestatin is a recently discovered twentythree-amino acid peptide transcribed on the preproghrelin gene, with a flanking conserved glycine residue at the end C-terminus ${ }^{(207)}$, and is secreted in a pulsatile manner ${ }^{(208)}$. Obestatin, administered both centrally and peripherally, produces an anorexigenic response, and reduces gut motility, gastric emptying and body weight ${ }^{(207,209)}$. Obestatin inhibited water imbibing in freely fed and watered rats and in food- and water-deprived rats ${ }^{(210)}$. The effects on water consumption preceded and were more pronounced than any effect on VFI, and Samson et al. ${ }^{(210)}$ concluded that the effects of obestatin on VFI may be secondary to an action of the peptide on imbibing water.

Zhang et al. ${ }^{(207)}$ reported that the C-terminus required amidation for obestatin to be biologically active. First reports indicated that obestatin binds to the orphan receptor GPR39, which shows similarities with GHS-R1a ${ }^{(207)}$. GPR39 mRNA was detected in the hypothalamus by RTPCR, and ${ }^{125} \mathrm{I}$-labelled obestatin binding sites were reported in the same region ${ }^{(209)}$. However, more recent studies failed to confirm the presence of specific obestatin binding to GPR39, or activation of this receptor by obestatin ${ }^{(211,212)}$. Furthermore, GPR39 expression has been detected in peripheral organs such as the jejunum, duodenum, stomach, ileum and liver, and to a lesser extent in the pancreas and kidney, but not in the pituitary or hypothalamus, which are presumed to be the central target organs for obestatin ${ }^{(212)}$. It has also been reported that obestatin does not cross the $\mathrm{BBB}^{(213)}$, suggesting that its role in VFI regulation may be at a peripheral tissue level.

Obestatin immunoreactivity positively correlated with insulin concentrations, and since acylated (active) ghrelin, which is also found in the pancreas, inhibits insulin secretion, it has been suggested that obestatin may potentiate insulin release $^{(214)}$. This was confirmed (JR Roche, JK Kay, AJ Sheahar, RC Boston and LM Chagas, unpublished results) in dairy cows, when obestatin-infused cows exhibited a two-fold increase in the area under the insulin curve following a glucose infusion, indicating a doubling of $\beta$-cell function. Similarly, glucose and insulin responses were lowered by 64 to $77 \%$ and 39 to $41 \%$, respectively, in mice that received either the full or truncated obestatin via intraperitoneal administration $4 \mathrm{~h}$ before a $15 \mathrm{~min}$ period of feeding ${ }^{(209)}$. This was accompanied by a 43 and $53 \%$ reduction in VFI respectively, confounding the effect of VFI and obestatin on insulin secretion. Green et al. (209) administered obestatin under basal and glucose challenges to determine whether effects were independent of changes in feeding. No alterations in glucose and insulin responses were evident, suggesting, at least in mice, that obestatin had no direct action on glucose or insulin secretion ${ }^{(209)}$.

In addition, both in vitro and in vivo studies on the administration of exogenous obestatin could not stimulate $\mathrm{GH}$ release as seen with both peripheral and central administration of ghrelin ${ }^{(208,210)}$, thereby showing that exogenous obestatin does not act directly on GH. However, when obestatin and ghrelin are co-administered, the in vivo ghrelin-induced GH secretion was markedly reduced ${ }^{(208)}$, implicating obestatin in an attenuation of ghrelin activity.

Clearly, as this is a newly discovered peptide and all work published to date is on rats and mice, more intensive studies need to be performed to validate the role of obestatin in maintaining energy balance, especially in the ruminant animal.

Peptide $Y Y_{3-36}$. Peptide $\mathrm{YY}$ is produced and secreted primarily from the enteroendocrine L cells in the distal end of the GI tract ${ }^{(215)}$. It was first isolated from porcine jejunal mucosa nearly 30 years ago ${ }^{(216)}$, is structurally homologous to NPY and pancreatic polypeptide, exhibiting the pancreatic polypeptide-fold motif and requiring the characteristic carboxy-terminal amidation required for bioactivity ${ }^{(176)}$, and is a known anorexigenic signal.

Cells that produce PYY are endocrine in nature and the peptide is secreted postprandially. The amount of the peptide secreted is partly in proportion to the energy content 
of the meal. However, it is also influenced by meal composition, with isoenergetic diets containing fat resulting in greater secretion ${ }^{(217)}$. Although concentrations rise within 30 min of eating, peak PYY does not occur for several hours $^{(218)}$. Peripheral administration of PYY has an anorexic effect in mice ${ }^{(219,220)}$, significantly delaying gastric emptying, gastric and pancreatic secretion, and the cephalic phase of gallbladder emptying ${ }^{(217)}$. Consistent with this, circulating concentrations of PYY are less in obese patients $^{(221)}$, and this attenuation has been associated with a reduced feeling of satiety. Peptide YY is therefore associated with a reduced GI passage rate, making PYY a likely candidate for the chemical messenger invoking the 'ileal brake' phenomenon, controlling the transit of feed through the GI tract to optimise nutrient digestion and absorption $^{(222)}$. In addition, PYY has been reported to increase active jejunal glucose transport in mice and $\operatorname{dogs}^{(222,223)}$. The reduced passage rate and the increase in glucose absorption would be expected to have anorexigenic effects.

Interestingly, central administration of PYY has orexigenic effects similar to NPY in mice ${ }^{(224)}$ and sheep ${ }^{(225)}$, suggesting that PYY does not have broad access to Y' receptors in the hypothalamus, but instead gains selective access to Y2 receptors, thereby blocking the orexigenic effects of NPY and AgRP, and allowing the expression of the anorexigenic melanocortin-producing cells ${ }^{(219)}$.

Despite the obvious anorexic effect of PYY, there is little information on PYY in ruminant animals. Onaga et al. ${ }^{(226)}$ studied the distribution and function of PYY in sheep. Mucosal concentrations of PYY were much less in sheep compared with those in the rat, and the sheep showed little fluctuation in plasma concentrations of PYY over a $48 \mathrm{~h}$ period, leaving the authors to conclude that PYY is unlikely to play the same role in ruminant animals as has been reported in single-stomached species. However, the infusion of PYY in sheep shortened the second cycle of migrating myoelectric complexes and delayed duodenal emptying ${ }^{(226)}$, consistent with the reported effects in single-stomached animals. Further research is required to determine the effect of physiological state and diet on the circulating concentrations of this peptide, and whether its exogenous administration alters VFI patterns in production farm animals.

Cannabinoids. The first steps in the identification of the role that cannabinoids play in animal physiology date back thousands of years, when the recognised therapeutic and psychotropic actions of Cannabis sativa were first documented in India ${ }^{(227)}$. In addition to their psychotropic effects (ataxia, short-term memory loss, a sense of time dilation, euphoria ${ }^{(228)}$, both endogenous and exogenous cannabinoids can have multiple physiological effects, including a general inhibition of neuroendocrine function, reducing $\mathrm{GH}$ response to hypoglycaemia, and reducing the secretion of testosterone and luteinising hormone ${ }^{(227)}$.

Cannabinoids (CB) work through a family of G-proteinlinked cell-surface receptors. To date two receptor subtypes have been identified (CB1 and CB2), with CB1 predominantly regarded as the prominent receptor of the CNS and some peripheral tissues and $\mathrm{CB} 2$, which is not expressed to any significant degree within the $\mathrm{CNS}^{(229)}$. According to Kirkham \& Williams ${ }^{(230)}$, it is generally agreed that the behavioural effects of cannabinoids are mediated by CB1. This is consistent with the suppression of VFI in laboratory animals treated with a selective CB1 antagonist, SR $141716^{(231,232)}$.

$\Delta^{9}$-Tetrahydrocannabinol. Pagotto et al. ${ }^{(227)}$ used two examples to highlight the importance of the endocannabinoid system in VFI regulation. The first was the discovery that there has been a high degree of evolutionary conservation in the endocannabinoid system, and the second being the recognition that high levels of endocannabinoids in maternal milk are critical for initiation of the suckling response in the neonate, at least in mice ${ }^{(233)}$. Consistent with this positive effect on VFI, $\Delta^{9}$-tetrahydrocannabinol $\left(\Delta^{9}-\mathrm{THC}\right)$, the primary active psychoactive constituent of marijuana, results in increased VFI when administered at low doses ${ }^{(227)}$. Williams et al. ${ }^{(234)}$ reported a four-fold increase in VFI following an oral dose of $1 \mathrm{mg} \Delta^{9}-\mathrm{THC} / \mathrm{kg}$ body weight; doses greater than this did not result in hyperphagia, probably because of the sedative effects of $\Delta^{9}$-THC. This orexigenic effect of $\Delta^{9}$-THC has been shown in rodents and humans, with $\Delta^{9}$-THC now prescribed for numerous anorexic-type conditions (for example, AIDS, cancer treatment). However, there is as yet no information available on its effects in ruminant animals, although hempseed was regarded as a source of high-quality rumen-bypass protein for cows and sheep ${ }^{(235)}$, with no detrimental effects on VFI reported when hemp meal was included at $20 \%$ of the ration DM. This lack of effect on VFI may be as a result of low concentrations of $\Delta^{9}$-THC in industrial hemp.

Endocannabinoids. Although the effect of exogenously administered cannabinoids is interesting, and their possible role in manipulating VFI should be investigated further in ruminant animals, the primary interest in this system in relation to VFI regulation is in the endogenous lipid ligands, most notably palmitoylethanolamide, donoylethanolamide and oleoylethanolamide.

Endocannabinoids have been reported to have both orexigenic and anorexigenic effects. Donoylethanolamide, otherwise known as anandamide or donoylethanolamide, has been shown to increase VFI in rodents. Williams \& Kirkham $^{(236)}$ demonstrated a donoylethanolamide-induced, CB1-mediated hyperphagia, providing important evidence for the involvement of a central cannabinoid system in the normal control of eating.

The most widely researched from a VFI-regulation point of view is oleoylethanolamide. Oleoylethanolamide is a natural analogue of the endogenous cannabinoid, anandamide (arachidonoylethanolamide) ${ }^{(237)}$, but it does not activate the cannabinoid receptors ${ }^{(238)}$. When administered intraperitoneally or orally, it has been shown to be a potent anorexigenic agent ${ }^{(239-241)}$. This effect is due to a selective change in the onset and frequency of feeding, indicating that the endocannabinoid system may alter the appetite value of ingested substances. Pagotto et al. ${ }^{(227)}$ suggested that this idea was consistent with the evidence in favour of a facilitatory function of the endocannabinoid system on brain 
reward circuits, bringing forward the onset of eating in satiated animals and increasing the incentive value of the feed eaten, regardless of the quality of the food.

Endocannabinoid regulation of VFI has been reported to be modulated by leptin. Di Marzo et al. ${ }^{(242)}$ reported that donoylethanolamide in the hypothalamus of mice was reduced with leptin infusion. Their data inferred that the leptin-induced anorexigenic effect may be, in part, endocannabinoid modulated, and a possible association between a hypothalamic overactivation of the endocannabinoid system and hyperphagia. Pagotto et al. ${ }^{(227)}$ points out, however, that the intrahypothalamic amount of endocannabinoids during the development of obesity must be investigated before such a general conclusion can be drawn. There are no reports of the effect of endocannabinoids on VFI in ruminant livestock, but considering its apparent importance in single-stomached physiology, it is also likely to play some role in ruminant VFI regulation, and further research is required to determine effects.

Comprehensive reviews of the central effects of insulin on energy homeostasis include Schwartz et al. ${ }^{(243)}$, Hillebrand et al. ${ }^{(8)}$ and Stanley et al. ${ }^{(39)}$ with ruminantspecific insulin reviews including Lobley ${ }^{(244)}$, Ingvartsen \& Andersen $^{(6)}$ and Henry ${ }^{(245)}$. A recent review specifically focused on the pancreatic hormones is Woods et al. ${ }^{(246)}$ These reviews provide a more complete coverage of the pancreatic hormones. Hormones secreted by the pancreas that are involved in VFI regulation include insulin, glucagon, amylin, pancreatic polypeptide (PP) and somato$\operatorname{statin}^{(247,248)}$.

Insulin. Insulin is a fifty-one-amino acid peptide hormone produced by the $\beta$-cells of the pancreatic islets of Langerhans. It plays a key role in energy homeostasis, reducing hepatic glucose production through its suppression of glucagon, and increasing glucose utilisation by peripheral tissues sensitive to its action. Basal insulin concentrations are generally proportional to body fat ${ }^{(94,95,249)}$, thereby providing a peripheral adiposity signal to the CNS for longterm regulation of body weight ${ }^{(34,243)}$. This relationship is more complex in production animals that undergo periods of weight change ${ }^{(249)}$, with the relationship evident in ruminant animals during periods of weight gain, but not during periods of weight loss or weight maintenance. In addition, insulin's role in glucose disposal indicates that it may also play a role in the short-term regulation of VFI.

Insulin rises within minutes of feed ingestion ${ }^{(250)}$, with cephalic-phase pancreatic $\beta$-cell secretion of insulin in ruminant animals stimulated by projections from the abomasum, pyloric and duodenal branches of the vagus nerves $^{(251)}$. In contrast, postprandial insulin secretion in ruminant animals is mediated by the central histaminergic system, with enhanced neural histamine levels elevating plasma insulin concentration and reducing $\mathrm{VFI}^{(252)}$.

In many studies, the short-term effects of insulin on VFI have been confounded by the resultant induced hypoglycaemia, and associated compensatory factors that may affect a return to eating. However, icv administration of insulin in sheep reduced VFI, depressed body weight after $6 \mathrm{~d}$, and halved peripheral serum insulin concentrations ${ }^{(253)}$, indicating a non-glucose-mediated insulin effect on VFI. Consistent with this, neuronal insulin receptor gene inactivation in mice increased VFI, obesity, insulin resistance and plasma insulin levels ${ }^{(254)}$.

Peripheral administration of insulin in hyperinsulinaemic-euglycaemic clamp studies has also confirmed that short-term VFI in ruminant species is decreased with insulin infusion, without hypoglycaemia ${ }^{(255,256)}$. Similarly, moderate level ( $6 \mathrm{mU} / \mathrm{kg}$ live weight) intra-jugular infusions of insulin, which elevated plasma insulin concentrations without depressing blood glucose, depressed VFI within $1 \mathrm{~h}$ of infusion, and over a $24 \mathrm{~h}$ period, in wether sheep fed roughage- or concentrate-based diets ${ }^{(257,258)}$. However, aspects of insulin's short-term action on VFI remain unclear. Central infusion of insulin depressed VFI and body weight in rats fed a high-carbohydrate diet, but not those fed a high-fat diet ${ }^{(259)}$, suggesting insulin's effects may be modified by diet. To further complicate matters, the ruminal microbial fermentation of ingested carbohydrates and a reliance on hepatic gluconeogenesis suggests that insulinmediated regulation of VFI in ruminant animals probably differs from single-stomached omnivores.

Most if not all of the insulin in the adult brain is of pancreatic origin $^{(243,260)}$. Insulin rapidly crosses the BBB by means of saturable receptor-mediated uptake ${ }^{(261)}$ in proportion to circulating concentrations ${ }^{(262)}$. Insulin receptors have been detected in the brain regions concerned with olfaction, the motivating and reward aspects of VFI driving orexigenic and anorexigenic signals, and the hypothalamic areas relating to energy metabolism and $\operatorname{VFI}^{(249,260,263,264)}$. Given its high concentration of insulin receptors ${ }^{(264)}$, the ARC appears to be the primary site for integrating peripheral adiposity signals at a neuronal level ${ }^{(34,265)}$.

Insulin has a double-pronged mode of action in controlling VFI, reducing the expression of orexigenic signals while heightening the feeling of satiety. Central insulin infusion to fasted rats inhibited prepro-NPY mRNA expression in the ARC, reducing NPY concentrations in the paraventricular nucleus of the hypothalamus ${ }^{(266)}$, while increasing POMC mRNA expression ${ }^{(267)}$. Consistent with this mode of action, antagonists to melanocortin have been reported to block the anorectic action of insulin ${ }^{(267)}$.

As well as a direct effect on the orexigenic and anorexigenic centres, it is likely that insulin acts indirectly on VFI by modulating the effect of leptin on these centres. Leptin and insulin share intracellular signalling pathways in hypothalamic neurons ${ }^{(268-270)}$, with insulin modulating the leptin signal transduction pathway in the hypothalamus of rats $^{(271)}$. Subcutaneous insulin injection of fasted rats increased ob mRNA levels to that of fed animals within $4 \mathrm{~h}$, independent of insulin effects on glucose levels or the effects of re-feeding. These results indicate a role for insulin in mediating the effects of food intake on short-term leptin gene expression in rodents ${ }^{(272)}$. Consistent with these data, plasma concentrations of insulin and leptin are positively correlated in lambs ${ }^{(273)}$ and gestating beef cows ${ }^{(274)}$. Similarly, dairy cow studies using a hyperinsulinaemiceuglycaemic clamp reported that plasma leptin and adipose leptin mRNA levels were increased by hyperinsulinaemia, 
although the response was attenuated in early lactation cows $^{(275,276)}$. Block et al. ${ }^{(275)}$ concluded that insulin is a positive regulator of leptin synthesis in dairy cows during periods of positive energy balance. In comparison, central leptin infusion was associated with an increase in plasma insulin in fasted $(60 \mathrm{~h})$ but not fed beef cows, inferring that insulin secretion is heightened by leptin under restricted feed intake ${ }^{(277)}$. While it is evident that insulin and leptin are closely linked, research is required to elucidate further the role of this interaction in ruminant animals under different physiological states and energy balances.

Further indirect effects of insulin are probably mediated through its effect on other orexigenic and anorexigenic agents. Roche et al. ${ }^{(278)}$ reported a rapid decline in circulating ghrelin concentrations in dairy cows subjected to an intravenous glucose infusion, and a gradual rise in the orexigenic agent with the insulin-mediated reduction in blood glucose. Insulin down-regulates phosphoenolpyruvate carboxykinase mRNA expression, a rate-limiting enzyme of gluconeogenesis, and this effect has been shown to be partially reversed by ghrelin ${ }^{(279)}$. Although plasma insulin levels were not affected when bovine ghrelin was injected into the jugular of steers fed once per $\mathrm{d}^{(161)}$ or 2 , 3-diaminopropanoic acid-octanoylated human ghrelin was continuously infused in dairy cows ${ }^{(199)}$, intramuscular ghrelin injections for $10 \mathrm{~d}$ before lambing decreased serum insulin concentrations in peripartum ewes ${ }^{(280)}$. In comparison, continuous subcutaneous infusion of the reputed anorexigenic agent, obestatin, doubled pancreatic $\beta$-cell function and resulted in double the insulin response to an intravenous glucose infusion in early lactating dairy cows (JR Roche, JK Kay, AJ Sheahan, RC Boston and LM Chagas, unpublished results).

Another hormone through which insulin exerts an anorexic effect could be CCK. Central insulin infusion in rats, at levels not affecting VFI, enhanced the anorexic effect of CCK and reduced meal size ${ }^{(281)}$. However, plasma insulin concentrations were not altered by intravenous injections of a CCK antagonist in dairy cows ${ }^{(176)}$, indicating CCK does not influence insulin secretion. Further research is required to clarify the relationship between insulin and other peptides involved in the regulation of VFI.

Although it is generally accepted that insulin increases with adiposity ${ }^{(94)}$, the relationship is not straightforward in production ruminant species. Weak correlations between plasma insulin concentration and BCS in mature lactating dairy cows led Bradford \& Allen ${ }^{(282)}$ to conclude that insulin is a poor adiposity signal for long-term VFI control in ruminant species. Similarly, Lents et al. ${ }^{(274)}$ reported that BCS only accounted for $12 \%$ of the variation in plasma insulin and leptin levels when gestating beef cows were grazed under similar pasture feeding conditions. However, there was a positive correlation between the variables when the same cows had differing nutrient intakes, indicating a possible interaction between chronic and acute energy balance status and insulin concentrations. This is consistent with data reported by Caldeira et al. ${ }^{(95)}$, who fed nonpregnant, non-lactating ewes at 30 or $200 \%$ of maintenance energy requirements over a period of 60-72 weeks and found different serum insulin profiles across the same BCS range, depending on whether animals were increasing or decreasing in adiposity. In furthering our understanding of this interaction, León et al. ${ }^{(249)}$ fed beef heifers to decline to, and then maintain, BCS at less than 2 (scale 1-9) for at least $25 \mathrm{~d}$; they then fed them to gain $1 \mathrm{~kg}$ body weight/d until a BCS of 6 was reached. They reported no relationship between insulin concentrations and BCS during the period of negative energy balance, but positive correlations were seen during weight gain. As circulating insulin concentrations depend on peripheral tissue sensitivity ${ }^{(265)}$, interpretation of peripheral insulin concentrations needs to account for both the direction of body-weight change and the animal's recent nutritional history, particularly when adiposity diverges from the physiological optimum.

Glucagon. Glucagon, a twenty-nine-amino acid peptide hormone, is secreted by the $\alpha$-cells of the pancreas in response to hypoglycaemia, and is a primary promoter of hepatic glycogenolysis and gluconeogenesis to increase circulating glucose concentrations ${ }^{(283,284)}$. Glucagon is a counter-regulatory hormone of insulin and the balanced action of these two hormones produces glucose homeostasis under the varying daily feeding events and exercise regimens of animals.

Glucagon is secreted immediately following food consumption and before nutrient absorption ${ }^{(285)}$ and reduces meal size in single-stomached animals ${ }^{(286)}$. This anorexigenic effect was confirmed by the intraperitoneal administration of pancreatic glucagon antibodies to feed-deprived Sprague-Dawley rats that resulted in increased meal size and duration ${ }^{(287)}$.

In rats, glucagon acts at receptor sites in the liver producing an anorexigenic signal transmitted via hepatic vagal afferents to the brain ${ }^{(288-290)}$ and acts at the ventromedial hypothalamus ${ }^{(285)}$, area postrema and the NST ${ }^{(291)}$. In ruminant animals, absorbed propionate stimulates glucagon release, mainly via stimulation of adrenergic $\alpha$-receptors, supporting the hypothesis that propionate is a major regulator of pancreatic endocrine secretion in ruminant animals ${ }^{(292)}$. Amino acid infusions in sheep have also been shown to increase glucagon secretion ${ }^{(293)}$.

There has been limited research on the influence of glucagon on VFI in ruminant species; however, the available evidence indicates that its influence on short-term VFI is consistent with that seen in single-stomached animals. Deetz \& Wangsness ${ }^{(258)}$ infused glucagon intrajugularly (9 ng/kg live weight) at meal initiation to wethers fed $a d$ libitum and demonstrated a $15.8 \%$ reduction in $24 \mathrm{~h}$ VFI compared with controls. She et al. ${ }^{(283)}$ reported that $14 \mathrm{~d}$ intravenous glucagon infusions reduced the normal increases in VFI of dairy cows post-partum. In contrast, a $24 \mathrm{~h}$ subcutaneous administration of glucagon $(15 \mathrm{mg} / \mathrm{d})$ to lactating dairy cows did not alter VFI, despite elevating blood glucagon levels ${ }^{(294)}$. Additionally, Caldeira et al. ${ }^{(295)}$ concluded that circulating glucagon was not a strong indicator of energy status in mature ewes. These results indicate that although glucagon may act as a short-term anorexigenic factor, it is unlikely to be a major regulator of longer-term VFI in ruminant animals.

Amylin. Amylin, also called islet amyloid polypeptide, is a thirty-seven-amino acid polypeptide co-secreted with 
insulin from the $\beta$-cells of the pancreas following nutrient ingestion $^{(175)}$. Amylin inhibits glucagon secretion ${ }^{(296,297)}$ and gastric emptying in rats ${ }^{(297,298)}$, indicative of a role in VFI regulation as a complementary hormone to insulin.

In rodents, both peripheral ${ }^{(299-301)}$ and central ${ }^{(302-303)}$ amylin action is to reduce acute VFI, through reduced meal size ${ }^{(304)}$. In obese rodents, this effect is accompanied by a reduction in fat mass and preservation of lean tissues, a halving of circulating insulin, and no change in energy expenditure $^{(301)}$. This meal-related anorexigenic effect is mediated through neurons in the area postrema of the hindbrain $^{(305,306)}$, possibly acting through an inhibition of the lateral hypothalamus pathways and the down-regulation of orexin expression ${ }^{(306)}$. Peripheral amylin administration reverses feed-deprivation activation of neurons in the lateral hypothalamus, and increases POMC and NPY mRNA expression in the $\mathrm{ARC}^{(301)}$.

The actions of amylin on gastric emptying and the reduction in VFI appear to be pharmacologically distinct $^{(298)}$ and the effects on VFI operate independently of the vagus nerve, unlike the effect on gastric emptying ${ }^{(298,299)}$. Further argument for amylin's role in VFI regulation is that it circulates in proportion to adiposity ${ }^{(307,308)}$. There is some evidence that amylin interacts synergistically with insu$\operatorname{lin}^{(300,309)}$ and leptin ${ }^{(309)}$ to reduce VFI and body weight in rodents. Central amylin may also play a role in longer-term VFI regulation in rodents as $14 \mathrm{~d}$ icv infusions of an amylin antagonist increased VFI and blood insulin concentrations, and elevated body fat by $30 \%{ }^{(310)}$. Central administration of ghrelin does not influence the anorexic effect of peripheral amylin $^{(309)}$. Therefore, amylin appears to affect short-term VFI directly, through anorexic stimuli in the hypothalamus, and indirectly, through slowing gastric emptying, while also interacting with adiposity signals to influence longer-term VFI and body-weight regulation.

Research of the role of amylin in VFI regulation in ruminant animals is limited. One study in pygmy goats reported an anorexigenic effect of peripheral amylin $(2 \mu \mathrm{g} / \mathrm{kg}$ body weight) infusion associated with reduced meal size ${ }^{(311)}$, consistent with its action in single-stomached animals. When rat amylin was infused in lactating goats, milk yield was not affected, but milk protein concentrations were reduced, while circulating concentrations of glucose and NEFA were increased ${ }^{(312)}$. These data indicate a variety of actions of amylin in ruminant animals, but further research is required to clarify these effects.

Pancreatic polypeptide. The pancreatic polypeptide family of thirty-six-amino acid peptide hormones includes PP, PYY and NPY. PP is released biphasically from the pancreatic Fcells in response to nutrient ingestion, gastric distension and vagal tone $^{(313)}$, and remains elevated in circulation in human subjects for at least $6 \mathrm{~h}$ postprandially ${ }^{(314)}$, potentially regulating inter-meal intervals ${ }^{(163)}$. Peripheral infusions of $\mathrm{PP}$ in human subjects indicate a dose-dependent reduction in orexigenic signals (immediate), and acute (meal offered $2 \mathrm{~h}$ post-infusion) as well as cumulative energy intake over $24 \mathrm{~h}^{(163,315)}$, but had no effect on plasma insulin, leptin, ghrelin, PYY or glucagon-like peptide-1, suggesting that the peripheral anorectic effect of PP is not mediated by these hormones ${ }^{(163)}$. In mice, peripheral administration of PP or transgenic modification for the over-expression of $\mathrm{PP}$ reduced VFI and gastric emptying, decreased the expression of the orexigenic peptides NPY, orexins and ghrelin, and resulted in reduced weight gain and fat mass ${ }^{(316,317)}$. Furthermore, transgenic mice had greater circulating CCK concentrations, with the induced anorexia moderated by CCK-1 receptor antagonists ${ }^{(318)}$. In fasting human subjects, peripheral ghrelin infusion produced an immediate and sustained elevation in circulating PP concentrations, and a biphasic elevation in circulating somatostatin ${ }^{(319)}$.

The area postrema has been implicated as the site activated by peripheral PP during the inhibition of VFI in rodents $^{(320)}$, although PP receptors are widely distributed in rodent brain tissues, including the ARC and the paraventricular nucleus of the hypothalamus, the forebrain and the $\mathrm{NST}^{(321)}$. Of the six types of receptors in the family, PP binds with greatest affinity to Y4 and Y5 receptors, although there are species differences in distribution of $\mathrm{PP}$ receptors amongst tissues and in their binding properties ${ }^{(322)}$.

In direct contrast to its anorexic actions when infused peripherally, central PP infusion increased VFI in mice for up to $4 \mathrm{~h}$ and promoted gastric emptying ${ }^{(323)}$. However, central infusion of PP (18 and $24 \mu \mathrm{g} / \mathrm{h}$ for $30 \mathrm{~h}$ ) as a Y4 agonist did not affect VFI in ovariectomised ewes ${ }^{(324)}$. The disparity in effects on VFI may be related to receptor expression or access at peripheral and central locations ${ }^{(171,313)}$. Like other pancreatic hormones involved in VFI regulation, research into the effects of PP in ruminant animals is limited. Carter et al. ${ }^{(325)}$ reported a postprandial peak in PP within 5 min of eating in lucerne-fed sheep, with increased PP concentrations 16 min before eating, possibly a result of cephalic-vagal stimulation. Despite the expectation of a more gradual pattern of postprandial nutrient release in forage-fed ruminant animals, PP peaked approximately $1 \mathrm{~h}$ after feeding, and returned to pre-prandial concentrations within $3-6 h^{(326)}$. Postprandial PP concentrations increased linearly with supplemental fat in the diets of lactating dairy cows, coincident with declining $\mathrm{VFI}^{(326)}$. Furthermore, circulating PP and CCK levels were significantly correlated, consistent with the data in single-stomached animals.

Somatostatin. Somatostatin is a fourteen-amino acid peptide secreted in the D-cells of the endocrine pancreas, acting locally to inhibit the secretion of insulin ${ }^{(327)}$ and centrally to inhibit somatotropin production. It is also present in the brain and GI tract. In ruminant animals, somatostatin immunoreactive fibres are present in the hypothalamic paraventricular, ventromedial, and ARC, and the median eminence ${ }^{(328,329)}$, and are significantly colocalised with leptin receptors ${ }^{(116)}$. In rats, central somatostatin counteracts the suppression in VFI mediated by leptin, reducing leptin receptor responsiveness ${ }^{(330)}$. Leptin infusion reduced hypothalamic somatostatin release ${ }^{(331)}$, and, in human subjects, systemic ghrelin injection produced a biphasic (15 and $120 \mathrm{~min})$ rise in circulating somatostatin and an associated decrease in circulating insulin ${ }^{(319)}$. Hence, somatostatin probably plays a role in long-term energy homeostasis.

Circulating plasma somatostatin levels increase in response to feeding ${ }^{(332)}$, acting to reduce VFI, with vagotomy and food deprivation removing its 
intake-suppressive effects ${ }^{(333)}$. Cattle immunised against somatostatin consumed more DM, had greater daily weight gain, and used feed more efficiently than control animals ${ }^{(334)}$. In comparison, undernutrition in ewes was associated with reduced somatostatin in the paraventricular and ventromedial nuclei of the hypothalamus ${ }^{(335)}$.

\section{The somatotropic axis}

The somatotropic axis, consisting of $\mathrm{GH}$, the somatomedins, insulin-like growth factor (IGF-I and II) and associated carriers and receptors, is one of the most well-researched hormone systems in mammals, playing a key role in the regulation of physiological and metabolic processes.

$\mathrm{GH}$ release from the anterior pituitary is pulsatile and is primarily regulated by two antagonistic hypothalamic hormones, GRF (also known as GH-releasing hormone; synthesised in the ARC), which stimulates $\mathrm{GH}$ release, and somatostatin (located in the paraventricular nucleus), which inhibits GH secretion ${ }^{(336)}$. In addition ghrelin, a natural ligand of the GHS-R, acts synergistically with GRF to stimulate $\mathrm{GH}$ release ${ }^{(155)}$. GH release is also under negative feedback regulation. IGF-I and GH act on the anterior pituitary to inhibit GH release, on the NPY neurons in the ARC to inhibit GRF secretion, and on the somatostatin neurons in the paraventricular nucleus to stimulate somatostatin release (336-341) $^{\text {. }}$

$\mathrm{GH}$ is essentially an anabolic hormone that acts, either directly on target tissues or via the somatomedins, to mediate numerous physiological systems ${ }^{(342)}$. Administration of bovine somatotropin consistently increases milk production in dairy cows. In short-term studies this galactopoietic response occurs without an increase in VFI, but long-term administration of bovine somatotropin is accompanied by a gradual increase in VFI to support the greater milk production ${ }^{(343)}$.

In addition to the positive effects of $\mathrm{GH}$ on metabolism and subsequent VFI, the somatotropic axis can also influence the CNS directly ${ }^{(344)}$. Receptors for GH and IGF-I and -II are present in many areas of the brain including the hippocampus, pituitary and hypothalamus, and $\mathrm{GH}$ and IGF can pass the BBB, although the mechanisms of transport are not yet completely understood. Furthermore, GH and IGF-I and -II can be produced in the brain, thereby acting via paracrine and autocrine mechanisms ${ }^{(344)}$. Much research has focused on determining which factors of the somatotropic axis are responsible for the increased VFI associated with longer-term infusion of $\mathrm{GH}$, and by which mechanism VFI is regulated.

A series of experiments demonstrated that icv injections of rat hypothalamic GRF, in pmol doses, increased VFI by $25-75 \%$ in both food-deprived and free-feeding rats. However, icv injections of a structurally related but physiologically inactive peptide, and peripheral administration of either GRF or GH did not influence VFI, indicating a direct action of GRF on mechanisms mediating $\mathrm{VFI}^{(345-347)}$.

The direct effect of GRF on feeding behaviour, independent of its GH-releasing properties, was supported by electrophysiological results, which demonstrated that iontophoretically applied GRF can influence neuronal membrane excitability, indicating that GRF has neurotransmitter and neuromodulatory actions. Further support for a direct central action of GRF on neural systems involved in VFI is that facilitatory feeding effects of icv GRF in rats and sheep are only evident at low pmol doses ${ }^{(345,347-349)}$, while higher doses (i.e. $4 \mathrm{nmol}$ ), which are comparable with icv GRF doses that stimulate $\mathrm{GH}$ release ${ }^{(350)}$, suppress feeding in rats ${ }^{(347)}$. In addition, the increased VFI following icv GRF administration is reversed by the opioid antagonist naloxone, in doses that do not influence basal VFI; these data indicate that opioid feeding systems are likely to be involved in the VFI-stimulatory effects of $\mathrm{GRF}^{(346)}$.

Neurons associated with GRF originate in the ARC and project to various hypothalamic sites distal to the portal blood vessels (major pathway to stimulate $\mathrm{GH}$ release). Vaccarino \& Hayward ${ }^{(351)}$ demonstrated that GRF was effective at stimulating VFI in rats when injected into the suprachiasmatic nucleus/medial preoptic area (SCN/ MPOA) of the hypothalamus, while injections into areas outside the SCN/MPOA did not alter VFI. The increased VFI observed following intra-SCN/MPOA microinjections was associated with increased meal length and rate of eating, with no effect on latency to onset of eating, suggesting GRF is involved in maintenance rather than initiation of feeding ${ }^{(351)}$

In addition to GRF, GH-releasing peptides (GHRP) increase VFI in rats ${ }^{(352-354)}$. This class of small peptides stimulates $\mathrm{GH}$ secretion and, to a lesser degree, prolactin and adrenocorticotropin release ${ }^{(355,356)}$. In the hypothalamus, GHRP stimulate the release of $\mathrm{GRF}^{(357)}$, while in the pituitary, the secretagogues act as an amplifier, directly stimulating $\mathrm{GH}$ release and potentiating the effect of the endogenous GRF on GH secretion, and as a functional somatostatin antagonist ${ }^{(355,356)}$.

Central administration of the GHRP KP-102 in pmol doses increased VFI in free-feeding rats, and acted synergistically when administered with $\mathrm{GRF}^{(353)}$. In addition, the KP-102-induced increase in VFI was not inhibited by prior treatment with a GRF antagonist, although this pre-treatment completely blocked the GRFstimulated increase in VFI. Locke et al. ${ }^{(358)}$ also demonstrated that icv administration of GHRP-6 stimulated eating in sated Sprague-Dawley rats, but did not affect plasma $\mathrm{GH}$ in a dose-response manner. These studies suggest the GHRP-induced increase in VFI is independent of its GRF-releasing properties, and is possibly mediated by specific GHRP receptors in the $\operatorname{ARC}^{(352,353,358)}$.

In addition to GH, GFR and GHRP, IGF also play a role in the regulation of VFI. Initial experiments using icv injections of insulin-like activities (an IGF-enriched preparation) inhibited GH pulses and decreased VFI in rats ${ }^{(359)}$. In an attempt to determine which IGF was involved in this response, Lauterio et al. ${ }^{(360)}$ injected purified IGF-I, IGF-II and insulin icv into free-feeding rats. IGF-II injections decreased VFI in a dose-dependent manner in the $24 \mathrm{~h}$ following peptide administration, whereas IGF-I and insulin had no effect on either parameter. Lauterio et al. ${ }^{(360)}$ also detected the presence of IGF-II but not IGF-I in specific areas of the hypothalamus implicated in VFI regulation, which supported the evidence for a role of IGF-II in the central control of VFI. Foster et al. ${ }^{(253)}$ supported the lack of effect 
of IGF-I on VFI regulation, when a $6 \mathrm{~d}$ icv infusion of IGF-I did not alter VFI or body weight in sheep. Interestingly, Foster et al. ${ }^{(253)}$ demonstrated a $40 \%$ reduction in VFI and body weight following $6 \mathrm{~d}$ icv infusion of insulin, consistent with insulin's chronic anorexigenic role in feeding behaviour $^{(360-364)}$.

\section{Fetal programming and epigenetics}

The long-term influence of maternal nutrition and other environmental influences during fetal development on postnatal growth and metabolism are increasingly realised ${ }^{(365)}$. The terms epigenetics and 'fetal programming' encompass genetic modifications in the offspring and their descendants following exposure of the pregnant mother to 'abnormal' conditions, such as under- or overnutrition or excessive stress ${ }^{(366)}$.

This concept of 'fetal programming' has been extensively investigated in both single-stomached and ruminant species $^{(367-369)}$, but the primary focus of this research has been in relation to its role in the onset of adult disease. However, there is some evidence that perinatal nutrition might affect the regulation of VFI in the adult ${ }^{(370)}$.

It is now accepted that both fetal and neonatal undernutrition have a determining effect on risk of obesity later in life, because of altered pancreatic functioning and insulin signalling ${ }^{(371)}$, and changes in programming of the young to store fat $^{(372)}$. It is, therefore, appropriate to hypothesise an effect of fetal programming on VFI regulation. Consistent with this, a $30 \%$ reduction in maternal nutrition during gestation and lactation induced a significant increase in VFI, obesity and hyperleptinaemia in rat offspring ${ }^{(373)}$. In comparison, a similar reduction in nutrient supply to adult sheep in the final third of gestation did not affect VFI between weaning and 2 years of age ${ }^{(374)}$, but a $50 \%$ reduction in nutrient intake resulted in a reduced insulin response and increased adipose lipolytic capacity $^{(375,376)}$. In rats, a similar impairment of the pancreatic function following gestational undernutrition has been attributed to epigenetic modifications inducing a progressive deterioration of insulin secretion in response to a glucose challenge ${ }^{(377)}$. Increased abdominal and subcutaneous fat in male lambs born to ewes undergoing a period of feed restriction (50\% of control group) between day 28 and 78 of pregnancy ${ }^{(375)}$ also suggests an effect of early gestational nutrition on physiological processes that interact with VFI regulation. This provides a potential effect of maternal undernutrition on VFI regulation in the offspring, irrespective of the timing of the nutritional insult. Unfortunately, VFI of the offspring was not measured in these studies.

The nature of the neural pathways affected by fetal programming is unknown. The programming of an increased feeding drive by undernutrition during the neonatal period could be leptin mediated; leptin has a documented tropic effect on the postnatal development of the projections from the ARC involved in the regulation of VFI and metabolism ${ }^{(378,379)}$. Further investigation targeting specific genes encoding for neuronal signals controlling VFI is necessary, in both ruminant and non-ruminant animals, to demonstrate the existence of a fetal programming effect on
VFI itself and not only a programming of the hormonal control of nutrient partitioning.

\section{Unique aspects of digestion in ruminant animals}

With regards to managing animals in order to increase VFI, the factors stimulating the production of the signals regulating VFI are as important as the signals themselves. Many of the regulatory factors identified are secreted in response to a specific nutrient ${ }^{(380)}$. Therefore, even though glucose has been reported to have a similar effect on VFIregulatory signalling peptides in ruminant animals ${ }^{(277)}$ as it has in single-stomached species, microbial fermentation is the primary process of feed digestion in ruminant animals. Thus, circulating VFA concentrations ${ }^{(381-383)}$, amino acids ${ }^{(293)}$ and lipids ${ }^{(326)}$ are more likely than glu$\operatorname{cose}^{(21,292,381)}$ to be the nutrients stimulating regulatory mechanisms in these species.

Additional complicating factors in ruminant animals include the dependence on gluconeogenesis for glucose production and a greater degree of insulin resistance than single-stomached omnivores ${ }^{(384,385)}$. Rumen fermentation also produces a more constant supply of nutrients and consequently plasma insulin concentrations tend to be lower and exhibit less diurnal variation than reported in singlestomached species $^{(250,386)}$.

Ruminal infusion of VFA has been reported to reduce $\mathrm{VFI}^{(387)}$, although it is still unclear as to how much of this anorexia is a result of local osmolarity effects or circulating signalling effects following absorption ${ }^{(21)}$. Infusion of propionate at physiologically relevant rates has been reported to increase plasma insulin concentrations ${ }^{(382)}$, providing a possible mechanism by which propionate could induce satiety. However, Allen et al. ${ }^{(250)}$ highlighted that the hypophagic effects of propionate have been observed without increases in insulin, indicating a non-insulinmediated role for propionate in VFI regulation.

Consistent with these data indicating a role for ruminally derived VFA in VFI regulation, the effect of VFA appears to be compounding, with combined infusions of acetate and propionate having a greater anorexigenic effect than with either of the VFA infused alone ${ }^{(388)}$. In addition, animals become increasingly sensitive to VFA infusions with greater internal VFA production ${ }^{(21)}$, indicating that VFA provide a measure of the short-term energy status of the animal to the CNS. However, further research is required to determine the effect of products of digestion in ruminant animals on circulating factors known to influence VFI, and to determine the relationship between grazing/foraging behaviour and the increase and decrease of these circulating peptides, to better define the causative role that physiological anorexogenic and orexigenic factors have on meal onset and cessation.

In addition to normal meal termination, the provision of supplements to grazing ruminant animals reduces time spent grazing ${ }^{(19)}$. This is unlikely to be the result of physical factors because the effect is evident in cows fed more energy-dense supplements based on cereal grains and when the base forage is highly digestible. This 'substitution' effect is possibly a result of increased VFA production, and the passage of food into the duodenum increasing the secretion of peptides. Roche et al. ${ }^{(156)}$ reported a reduction in plasma 
ghrelin concentrations in grazing cows $2 \mathrm{~h}$ following concentrate supplementation, consistent with a reduction in time spent grazing. An additional contributory factor where cereal grains are being fed may be in the passage of starch to the duodenum. Although most starch eaten by ruminant animals is fermented by the rumen microorganisms, some escapes this process and proceeds to the small intestine. Swanson et al. ${ }^{177)}$ reported a $31 \%$ increase in circulating CCK-8 concentrations in ruminant animals abomasally infused with starch, presumably signalling the NST via the vagus nerve to terminate the meal. Further research is required to gain a greater understanding of the neuroendocrine basis for substitution rate.

\section{Conclusions}

The understanding of how VFI is regulated in singlestomached species has improved dramatically in recent decades, and, although data are limited, there is increasing evidence that the same mechanisms are responsible for VFI regulation in domesticated ruminant animals. Information regarding metabolic state is transmitted to the orexigenic and anorexigenic regulation centres of the brain through physical stimulation in the rumeno-reticulum and through metabolic 'feedback' factors derived from the pituitary gland, adipose tissue, stomach/abomasum, intestine, pancreas and other organs. These signals can act directly on the neurons located in the ARC of the medio-basal hypothalamus, a key integration and appetite control centre of the brain. Further research is required to determine the relationship between these hormones and grazing/foraging behaviour in ruminant species, to enable a greater understanding of the nutritional and management factors influencing VFI, and thereby enabling the design of more efficient production systems.

\section{Acknowledgements}

There are no conflicts of interest.

\section{References}

1. Forbes JM \& Provenza FD (2000) Integration of learning and metabolic signals into a theory of dietary choice and food intake. In Ruminant Physiology: Digestion, Metabolism, Growth and Reproduction, pp. 3-19 [P Cronje, editor]. Wallingford, UK: CAB International.

2. Ulyatt MJ \& Waghorn GC (1993) Limitations to high levels of dairy production from New Zealand pastures. In Improving the Quality and Intake of Pasture Based Diets for Lactating Dairy Cows, pp. 11-32 [NJ Edwards and WJ Parker, editors]. Palmerston North, NZ: Department of Agriculture and Horticulture Systems Management, Massey University.

3. Muller LD (1993) Limitations of pasture for high production by dairy cows - a US perspective. In Improving the Quality and Intake of Pasture Based Diets for Lactating Dairy Cows, pp. 33-58 [NJ Edwards and WJ Parker, editors]. Palmerston North, NZ: Department of Agriculture and Horticulture Systems Management, Massey University.
4. Kolver ES \& Muller LD (1998) Performance and nutrient intake of high producing Holstein cows consuming pasture or a total mixed ration. J Dairy Sci 81, 1403-1411.

5. Linnane M, Horan B, Connolly J, et al. (2004) The effect of strain of Holstein-Friesian and feeding system on grazing behaviour, herbage intake and productivity in the first lactation. Anim Sci 78, 169-178.

6. Ingvartsen KL \& Andersen JB (2000) Integration of metabolism and intake regulation: a review focussing on periparturient animals. J Dairy Sci 83, 1573-1597.

7. Van Soest PJ (1994) Nutritional Ecology of the Ruminant, 2nd ed. NewYork: Cornell University Press.

8. Hillebrand JJG, de Wied D \& Adan RAH (2002) Neuropeptides, food intake and body weight regulation: a hypothalamic focus. Peptides 23, 2283-2306.

9. Forbes JM (1995) Voluntary Food Intake and Diet Selection in Farm Animals, 1st ed. Wallingford, UK: CAB International.

10. Allen MS (2000) Effects of diet on short-term regulation of feed intake by lactating dairy cattle. J Dairy Sci $\mathbf{8 3}$, 1598-1624.

11. Castonguary TW \& Stern JS (1990) Hunger and appetite. In Present Knowledge in Nutrition, 6th ed., pp. 13-22 [ML Brown, editor]. Washington, DC: ILSI Press.

12. Underwood EJ \& Suttle NF (1999) The Mineral Nutrition of Livestock, 3rd ed. Wallingford, UK: CAB International.

13. Woods SC (2004) Gastrointestinal satiety signals I. An overview of gastrointestinal signals that influence food intake. Am J Physiol Gastrointest Liver Physiol 286, G7-G13.

14. Hafez ESE \& Schein MW (1962) The behaviour of cattle. In Behaviour of Domestic Ruminants, pp. 247-296 [ESE Hafez, editor]. London: Bailliere, Tindall and Cox Ltd.

15. Hafez ESE \& Scott JP (1962) The behaviour of sheep and goats. In Behaviour of Domestic Ruminants, pp. 297-333 [ESE Hafez, editor]. London: Bailliere, Tindall and Cox Ltd.

16. Dalley DE, Roche JR, Moate PJ, et al. (2001) More frequent allocation of herbage does not improve the milk production of dairy cows in early lactation. Aus J Exp Agric 41, 593-599.

17. Grant RJ \& Albright JL (2000) Feeding behaviour. In Farm Animal Metabolism and Nutrition, pp. 365-382 [JPF D'Mello, editor]. Wallingford, UK: CABI Publishing.

18. Thorne PL, Jago JG, Kolver ES, et al. (2003) Diet and genotype affect feeding behaviour in Holstein-Friesian dairy cows. Proc N Z Soc Anim Prod 63, 124-127.

19. Bargo F, Muller LD, Kolver ES, et al. (2003) Invited review: production and digestion of supplemented dairy cows on pasture. J Dairy Sci 86, 1-42.

20. Farnighan DAH \& White CC (1993) The role of propionate and acetate in the control of food intake in sheep. Br J Nutr 70, 37-46.

21. Faverdin P (1999) The effect of nutrients on feed intake in ruminants. Proc Nutr Soc 58, 523-531.

22. Dahl GE, Buchanan BA \& Tucker HA (2000) Photoperiodic effects on dairy cattle: a review. J Dairy Sci 83, 885-893.

23. Voelker JA, Burato GM \& Allen MS (2002) Effects of pretrial milk yield on responses of feed intake, digestion, and production to dietary forage concentration. J Dairy Sci 85, 2650-2661.

24. Allen MS (1996) Physical constraints on voluntary intake of forages by ruminants. J Anim Sci 74, 3063-3075.

25. M'Hamed D, Faverdin P \& Verite R (2001) Effects of the level and source of dietary protein on intake and milk yield in dairy cows. Anim Res 50, 205-211. 
26. Mertens DR (1992) Nonstructural and structural carbohydrates. In Large Dairy Herd Management, p. 219 [HH Van Horn and CJ Wilcox, editors]. Champaign, IL: American Dairy Science Association.

27. Welch JG (1967) Appetite control in sheep by indigestible fibers. J Anim Sci 26, 849-854.

28. Dado RG \& Allen MS (1995) Intake limitations, feeding behavior, and rumen function of cows challenged with rumen fill from dietary fiber or inert bulk. J Dairy Sci 78, $118-133$.

29. Dado RG \& Allen MS (1996) Enhanced intake and production of cows offered ensiled alfalfa with higher neutral detergent fiber digestibility. J Dairy Sci 79, 418-428.

30. Faverdin P \& Bareille N (1994) Effects of timing of rumen energy supply on food intake in lactating dairy cows. Ann Zootech 43, 286.

31. Seoane JR, Baile CR \& Martin FH (1972) Humoral factors modifying feeding behavior of sheep. Physiol Behav 8, 993-995.

32. Hervey GR (1959) The effects of lesions in hypothalamus in parabiotic rats. $J$ Physiol 145, 336-352.

33. Cummings DE \& Foster KE (2003) Ghrelin-leptin tango in body-weight regulation. Gastroenterology 124, 1532-1535.

34. Schwartz MW, Woods SC, Porte D Jr, et al. (2000) Central nervous system control of food intake. Nature 404, $661-671$.

35. Hetherington AW \& Ranson SW (1940) Hypothalamic lesions and adiposity in the rat. Anat Rec 78, 149-172.

36. Anand BK \& Brobeck JR (1951) Localization of a feeding center in the hypothalamus of the rat. Proc Soc Exp Biol Med 77, 323-324.

37. Baillie P \& Morrison SD (1963) The nature of the suppression of food intake by lateral hypothalamic lesions in rats. $J$ Physiol 165, 227-245.

38. Randall W, Lakso V \& Liittschwager J (1969) Lesioninduced dissociations between appetitive and consummatory grooming behaviors and their relationship to body weight and food intake rhythms. J Comp Physiol Psychol 68, 476-483.

39. Stanley S, Wynne K, McGowan B, et al. (2005) Hormonal regulation of food intake. Physiol Rev 85, 1131-1158.

40. Kennedy GC (1953) The role of depot fat in the hypothalamic control of food intake in the rat. Proc $R$ Soc Lond B Biol Sci 140, 578-592.

41. Brobeck JR (1946) Mechanism of the development of obesity in animals with hypothalamic lesions. Physiol Rev 26, 541-559.

42. Stellar E (1954) The physiology of motivation. Psychol Rev 101, 301-311.

43. Ritter RC, Brenner LA \& Tamura CS (1994) Endogenous CCK and the peripheral neural substrates of intestinal satiety. Ann N Y Acad Sci 713, 255-267.

44. Harris RB (2000) Leptin - much more than a satiety signal. Ann Rev Nutr 20, 45-75.

45. Sakata T (1991) Newly detected endogenous substances: their physiological implications on food intake. Agressologie 32, 215-219.

46. Forbes JM \& Barrio JP (1992) Abdominal chemo- and mechanosensitivity in ruminants and its role in the control of food intake. Exp Physiol 77, 27-50.

47. Leslie RA, Gwyn DG \& Hopkins DA (1982) The central distribution of the cervical vagus nerve and gastric afferent and efferent projections in the rat. Brain Res Bull 8, 37-43.

48. Shapiro RE \& Miselis RR (1985) The central organization of the vagus nerve innervating the stomach of the rat. $J$ Comp Neural 238, 473-488.
49. Zarbin MA, Innis RB, Wamsley JK, et al. (1983) Autoradiographic localization of cholechystokinin receptors in rodent brain. J Neurosci 3, 877-906.

50. Moran TH, Robinson PH, Goldrich MS, et al. (1986) Two brain cholecystokinin receptors: implications for behavioural actions. Brain Res 362, 175-179.

51. Davson H, Welch K \& Segal MB (1987) Physiology and Pathophysiology of the Cerebrospinal Fluid. London: Churchill Livingstone.

52. Oldendorf WH (1975) Permeability of the blood-brain barrier. In The Basic Neurosciences, pp. 279-289 [DB Tower, editor]. New York: Raven Press.

53. Stein LJ, Dorsa DM, Baskin DG, et al. (1987) Reduced effect of experimental peripheral hyperinsulinemia to elevate cerebrospinal fluid insulin concentrations of obese Zucker rats. Endocrinology 121, 1611-1615.

54. Banks WA (2006) The blood-brain barrier as a regulatory interface in the gut-brain axes. Physiol Behav 89, 472-476.

55. Raz A \& Livne A (1973) Differential effects of lipids on the osmotic fragility of erythrocytes. Biochim Biophys Acta 311, 222-229.

56. Sztriha L \& Betz AL (1991) Oleic acid reversibly opens the blood-brain barrier. Brain Res 550, 257-262.

57. Strubbe JH, Porte D Jr \& Woods SC (1988) Insulin responses and glucose levels in plasma and cerebrospinal fluid during fasting and refeeding in the rat. Physiol Behav 44, 205-208.

58. Adam CL \& Mercer JG (2004) Appetite regulation and seasonality: implications for obesity. Proc Nutr Soc 63, 413-419.

59. Adam CL, Findlay PA \& Miller DW (2006) Blood-brain leptin transport and appetite and reproductive neuroendocrine responses to intracerebroventricular leptin injection in sheep: influence of photoperiod. Endocrinology 147, 4589-4598.

60. Schwartz MW, Seeley RJ, Campfield LA, et al. (1996) Identification of targets of leptin action in rat hypothalamus. J Clin Invest 98, 1101-1106.

61. Elias CF, Aschkenasi C, Lee C, et al. (1999) Leptin differentially regulates NPY and POMC neurons projecting to the lateral hypothalamic area. Neuron 23, 775-786.

62. Schwartz MW, Seeley RJ, Woods SC, et al. (1997) Leptin increases hypothalamic pro-opiomelanocortin mRNA expression in the rostral arcuate nucleus. Diabetes 46, 2119-2123.

63. Cowley MA, Smart JL, Rubinstein M, et al. (2001) Leptin activates anorexigenic POMC neurons through a neural network in the arcuate nucleus. Nature 411, 480-484.

64. Korner J, Savontaus E, Chua SC Jr, et al. (2001) Leptin regulation of AgRP and NPY mRNA in the rat hypothalamus. J Neuroendocrinol 13, 959-966.

65. Clark JT, Kalra PS, Crowley WR, et al. (1984) Neuropeptide Y and human pancreatic polypeptide stimulate feeding behavior in rats. Endocrinology 115, 427-429.

66. Morley JE, Levine AS, Gosnell BA, et al. (1987) Effect of neuropeptide $\mathrm{Y}$ on ingestive behaviors in the rat. Am J Physiol 252, R599-R609.

67. Stanley BG, Kyrkouli SE, Lampert S, et al. (1986) Neuropeptide Y chronically injected into the hypothalamus: a powerful neurochemical inducer of hyperphagia and obesity. Peptides 7, 1189-1192.

68. Miner JL, Della-Fera MA, Paterson JA, et al. (1989) Lateral cerebroventricular injection of neuropeptide Y stimulates feeding in sheep. Am J Physiol Regul Integr Comp Physiol 257, R383-R387. 
69. Kalra SP, Dube MG, Sahu A, et al. (1991) Neuropeptide Y secretion increases in the paraventricular nucleus in association with increased appetite for food. Proc Natl Acad Sci U S A 88, 10931-10935.

70. Archer ZA, Rhind SM, Findlay PA, et al. (2002) Contrasting effects of different levels of food intake and adiposity on LH secretion and hypothalamic gene expression in sheep. $J$ Endocrinol 175, 383-393.

71. Kurose Y, Iqbal J, Rao A, et al. (2005) Changes in expression of the genes for the leptin receptor and the growth hormone-releasing peptide/ghrelin receptor in the hypothalamic arcuate nucleus with long-term manipulation of adiposity by dietary means. J Neuroendocrinol 17, $331-340$.

72. Widdowson PS, Upton R, Henderson L, et al. (1997) Reciprocal regional changes in brain NPY receptor density during dietary restriction and dietary-induced obesity in the rat. Brain Res $\mathbf{7 7 4}, 1-10$.

73. Chronwall BM, DiMaggio DA, Massari VJ, et al. (1985) The anatomy of neuropeptide-Y-containing neurons in rat brain. Neuroscience 15, 1159-1181.

74. Bi S, Scott KA, Kopin AS, et al. (2004) Differential roles for cholecystokinin a receptors in energy balance in rats and mice. Endocrinology 145, 3873-3880.

75. Bi S, Robinson BM \& Moran TH (2003) Acute food deprivation and chronic food restriction differentially affect hypothalamic NPY mRNA expression. Am J Physiol Regul Integr Comp Physiol 285, R1030-R1036.

76. Li C, Chen P \& Smith MS (1998) Neuropeptide Y(NPY) neurons in the arcuate nucleus (ARH) and dorsomedial nucleus (DMH), areas activated during lactation, project to the paraventricular nucleus of the hypothalamus (PVH). Regul Pept 75, 93-100.

77. Sorensen A, Adam CL, Findlay PA, et al. (2002) Leptin secretion and hypothalamic neuropeptide and receptor gene expression in sheep. Am J Physiol Regul Integr Comp Physiol 282, R1227-R1235.

78. Erickson JC, Clegg KE \& Palmiter RD (1996) Sensitivity to leptin and susceptibility to seizures of mice lacking neuropeptide Y. Nature 381, 415-421.

79. Pedrazzini T, Seydoux J, Kunstner P, et al. (1998) Cardiovascular response, feeding behavior and locomotor activity in mice lacking the NPY Y1 receptor. Nat Med $\mathbf{4}$, $722-726$.

80. Lincoln GA \& Richardson M (1998) Photo-neuroendocrine control of seasonal cycles in body weight, pelage growth and reproduction: lessons from the HPD sheep model. Comp Biochem Physiol C Pharmacol Toxicol Endocrinol 119, 283-294.

81. Kim EM, O'Hare E, Grace MK, et al. (2000) ARC POMC mRNA and PVN $\alpha$-MSH are lower in obese relative to lean Zucker rats. Brain Res 862, 11-16.

82. Fan W, Boston BA, Kesterson RA, et al. (1997) Role of melanocortinergic neurons in feeding and the agouti obesity syndrome. Nature 385, 165-168.

83. Baker RA \& Herkenham M (1995) Arcuate nucleus neurons that project to the hypothalamic paraventricular nucleus: neuropeptidergic identity and consequences of adrenalectomy on mRNA levels in the rat. J Comp Neurol 358, $518-530$

84. ten Horst GJ, Luiten PG \& Kuipers F (1984) Descending pathways from hypothalamus to dorsal motor vagus and ambiguus nuclei in the rat. J Auton Nerv Syst 11, 59-75.

85. Peyron C, Tighe DK, van den Pol AN, et al. (1998) Neurons containing hypocretin (orexin) project to multiple neuronal systems. J Neurosci 18, 9996-10015.

86. Darwin C (1859) The Origin of Species. London: J Murray.
87. Bernard C (1856) Memoir of the Pancreas. New York: Academic Press.

88. Bernstein IL, Lotter EC, Kulkosky PJ, et al. (1975) Effect of force-feeding upon basal insulin levels of rats. Proc Soc Exp Biol Med 150, 546-548.

89. Mitchel JS \& Keesey RE (1977) Defense of a lowered weight maintenance level by lateral hypothalamically lesioned rats: evidence from a restriction-refeeding regimen. Physiol Behav 18, 1121-1125.

90. Oldham JD \& Emmans GC (1989) Prediction of responses to required nutrients in dairy cows. J Dairy Sci 72, 3212-3229.

91. Roche JR, Berry DP, Lee JM, et al. (2007) Describing the body condition score change between successive calvings: a novel strategy generalizable to diverse cohorts. J Dairy Sci 90, 4378-4396.

92. Holter JB, Slotnick MJ, Hayes HH, et al. (1990) Effect of prepartum dietary energy on condition score, postpartum energy, nitrogen partitions and lactation production responses. J Dairy Sci 73, 3502-3511.

93. Tolkamp BJ, Emmans GC \& Kyriazakis I (2006) Body fatness affects feed intake of sheep at a given body weight. $J$ Anim Sci 84, 1778-1789.

94. McCann JP, Bergman EN \& Beermann DH (1992) Dynamic and static phases of severe dietary obesity in sheep: food intakes, endocrinology and carcass and organ chemical composition. J Nutr 122, 496-505.

95. Caldeira RM, Belo AT, Santos CC, et al. (2007) The effect of long-term feed restriction and over-nutrition on body condition score, blood metabolites and hormonal profiles in ewes. Small Rumin Res 68, 242-255.

96. Broster WH \& Broster VJ (1998) Body score of dairy cows. $J$ Dairy Res 65, 155-173.

97. Roche JR, Macdonald KA, Burke CR, et al. (2007) Associations among body condition score, body weight and reproductive performance in seasonal-calving dairy cattle. $J$ Dairy Sci 90, 376-391.

98. Zhang Y, Proenca R, Maffei M, et al. (1994) Positional cloning of the mouse obese gene and its human homologue. Nature 372, 425-432.

99. Gimeno RE \& Klaman LD (2005) Adipose tissue as an active endocrine organ: recent advances. Curr Opin Pharmacol 5, 122-128.

100. Vague J \& Fenasse R (1965) The adipo-muscle ratio. Rev Fr Endocrinol Clin 6, 365-393.

101. Gunn TR \& Gluckman PD (1995) Perinatal thermogenesis. Early Hum Dev 42, 169-183.

102. Blache D, Zhang S \& Martin GB (2006) Dynamic and integrative aspects of the regulation of reproduction by metabolic status in male sheep. Reprod Nutr Dev 46, 379-390.

103. Chilliard Y, Delavaud C \& Bonnet M (2005) Leptin expression in ruminants: nutritional and physiological regulations in relation with energy metabolism. Domest Anim Endocrinol 29, 3-22.

104. Zieba DA, Amstalden M \& Williams GL (2005) Regulatory roles of leptin in reproduction and metabolism: a comparative review. Domest Anim Endocrinol 29, 166-185.

105. Blache D, Tellam R, Chagas LM, et al. (2000) Level of nutrition affects leptin concentrations in plasma and cerebrospinal fluid in sheep. J Endocrinol 165, 625-637.

106. Delavaud C, Bocquier F, Chilliard Y, et al. (2000) Plasma leptin determination in ruminants: effect of nutritional status and body fatness on plasma leptin concentration assessed by a specific RIA in sheep. $J$ Endocrinol 165, 519-526.

107. Ehrhardt RA, Slepetis RM, Siegal-Willott J, et al. (2000) Development of a specific radioimmunoassay to measure 
physiological changes of circulating leptin in cattle and sheep. J Endocrinol 166, 519-528.

108. Roche JR, Kolver ES \& Kay JK (2005) Influence of precalving feed allowance on periparturient metabolic and hormonal responses and milk production in grazing dairy cows. J Dairy Sci 88, 677-689.

109. Campfield LA, Smith FJ, Guisez Y, et al. (1995) Recombinant mouse OB protein: evidence for a peripheral signal linking adiposity and central neural networks. Science 269, 546-549.

110. Campfield LA \& Smith FJ (1998) Overview: neurobiology of OB protein (leptin). Proc Nutr Soc 57, 429-440.

111. Ahima RS, Saper CB, Flier JS, et al. (2000) Leptin regulation of neuroendocrine systems. Front Neuroendocrinol 21, 263-307.

112. Thomas SA, Preston JE, Wilson MR, et al. (2001) Leptin transport at the blood-cerebrospinal fluid barrier using the perfused sheep choroid plexus model. Brain Res 895, 283-290.

113. Adam CL, Archer ZA, Findlay PA, et al. (2002) Hypothalamic gene expression in sheep for cocaine- and amphetamine-regulated transcript, pro-opiomelanocortin, neuropeptide Y, agouti-related peptide and leptin receptor and responses to negative energy balance. Neuroendocrinology 75, 250-256.

114. Dyer CJ, Simmons JM, Matteri RL, et al. (1997) Leptin receptor mRNA is expressed in ewe anterior pituitary and adipose tissues, and is differentially expressed in hypothalamic regions of well-fed and feed-restricted ewes. Domest Anim Endocrinol 14, 119-128.

115. Iqbal J, Pompolo S, Considine RV, et al. (1999) Localization of leptin receptor-like immunoreactivity in corticotropes, somatotropes and gonadotropes in the ovine pituitary gland. Proc Endocr Soc Aust 42, 76.

116. Iqbal J, Pompolo S, Murakami T, et al. (2000) Localization of long-form leptin receptor in the somatostatin-containing neurons in the sheep hypothalamus. Brain Res 887, 1-6.

117. Williams LM, Adam CL, Mercer JG, et al. (1999) Leptin receptor and neuropeptide $\mathrm{Y}$ gene expression in the sheep brain. J Neuroendocrinol 11, 165-169.

118. Ahima RS (2005) Central actions of adipocyte hormones. Trends Endocrinol Metab 16, 307-313.

119. Archer ZA, Findlay PA, Rhind SM, et al. (2002) Orexin gene expression and regulation by photoperiod in the sheep hypothalamus. Regul Pept 104, 41-45.

120. Iqbal J, Pomolo S, Murakami T, et al. (2001) Immunohistochemical characterization of localization of long-form leptin receptor $(\mathrm{OB}-\mathrm{Rb})$ in neurochemically defined cells in the ovine hypothalamus. Brain Res 920, 55-64.

121. Hosoi T, Kawagishi T, Okuma Y, et al. (2002) Brain stem is a direct target for leptin's action in the central nervous system. Endocrinology 143, 3498-3504.

122. Morton GJ, Blevins JE, Williams DL, et al. (2005) Leptin action in the forebrain regulates the hindbrain response to satiety signals. J Clin Invest 115, 703-710.

123. Blache D, Celi P, Blackberry MA, et al. (2000) Decrease in voluntary feed intake and pulsatile luteinizing hormone secretion after intracerebroventricular infusion of recombinant bovine leptin in mature male sheep. Reprod Fertil Dev 12, 373-381.

124. Miller DW, Findlay PA, Morrison MA, et al. (2002) Seasonal and dose-dependent effects of intracerebroventricular leptin on LH secretion and appetite in sheep. $J$ Endocrinol 175, 395-404.

125. Adam CL, Archer ZA \& Miller DW (2003) Leptin actions on the reproductive neuroendocrine axis in sheep. Reprod Suppl 61, 283-297.
126. Clarke IJ, Henry B, Iqbal J, et al. (2001) Leptin and the regulation of food intake and the neuroendocrine axis in sheep. Clin Exp Pharmacol Physiol 28, 106-107.

127. Rhind SM, Archer ZA \& Adam CL (2002) Seasonality of food intake in ruminants: recent developments in understanding. Nutr Res Rev 15, 43-65.

128. Kadokawa H, Blache D, Yamada Y, et al. (2000) Relationships between changes in plasma concentrations of leptin before and after parturition and the timing of first postpartum ovulation in high producing Holstein dairy cows. Reprod Fertil Dev 12, 405-411.

129. Mann GE, Mann SJ, Blache D, et al. (2005) Metabolic variables and plasma leptin concentrations in dairy cows exhibiting reproductive cycle abnormalities identified through milk progesterone monitoring during the post partum period. Anim Reprod Sci 88, 191-202.

130. Blache D, Chagas LM \& Martin GB (2007) Nutritional inputs into the reproductive neuroendocrine control system - a multidimensional perspective. In Reproduction in Domestic Ruminants VI, pp. 123-139 [JI Juengel, JF Murray and MF Smith, editors]. Nottingham, UK: Nottingham University Press.

131. Ahima RS \& Flier JS (2000) Leptin. Annu Rev Physiol 62, 413-437.

132. Kershaw EE \& Flier JS (2004) Adipose tissue as an endocrine organ. J Clin Endocrinol Metab 89, 2548-2556.

133. Viengchareun S, Zennaro MC, Pascual-le Tallec L, et al. (2002) Brown adipocytes are novel sites of expression and regulation of adiponectin and resistin. FEBS Lett 532, 345-350.

134. Kadowaki $\mathrm{T} \&$ Yamauchi $\mathrm{T}$ (2005) Adiponectin and adiponectin receptors. Endocr Rev 26, 439-451.

135. Yamauchi T, Kamon J, Waki H, et al. (2003) Globular adiponectin protected ob/ob mice from diabetes and ApoEdeficient mice from atherosclerosis. J Biol Chem 278, 2461-2468

136. Matsuzawa Y (2005) Adiponectin: identification, physiology and clinical relevance in metabolic and vascular disease. Atheroscler Suppl 6, 7-14.

137. Steppan CM, Bailey ST, Bhat S, et al. (2001) The hormone resistin links obesity to diabetes. Nature 409, 307-312.

138. Tovar S, Nogueiras R, Tung LY, et al. (2005) Central administration of resistin promotes short-term satiety in rats. Eur J Endocrinol 153, R1-R5.

139. Savage DB, Sewter CP, Klenk ES, et al. (2001) Resistin/Fizz3 expression in relation to obesity and peroxisome proliferator-activated receptor- $\{\gamma\}$ action in humans. Diabetes 50, 2199-2202.

140. Valsamakis G, McTernan PG, Chetty R, et al. (2004) Modest weight loss and reduction in waist circumference after medical treatment are associated with favorable changes in serum adipocytokines. Metabolism 53, 430-434.

141. Steppan CM \& Lazar MA (2004) The current biology of resistin. J Intern Med 255, 439-447.

142. Rajala MW, Lin Y, Ranalletta M, et al. (2002) Cell typespecific expression and coregulation of murine resistin and resistin-like molecule- $\alpha$ in adipose tissue. Mol Endocrinol 16, 1920-1930.

143. Komatsu T, Itoh F, Mikawa S, et al. (2003) Gene expression of resistin in adipose tissue and mammary gland of lactating and non-lactating cows. $J$ Endocrinol 178, R1-R5.

144. Buchanan JB \& Johnson RW (2007) Regulation of food intake by inflammatory cytokines in the brain. Neuroendocrinology 86, 183-190.

145. Schobitz B, De Kloet ER \& Hosboer F (1994) Gene expression and function of interleukin 1, interleukin 6 and 
tumor necrosis factor in the brain. Prog Neurobiol 44, $397-432$.

146. Stenlof K, Wernstedt I, Fjallman T, et al. (2003) Interleukin6 levels in the central nervous system are negatively correlated with fat mass in overweight/obese subjects. $J$ Clin Endocrinol Metab 88, 4379-4383.

147. Wallenius V, Wallenius K, Ahrén B, et al. (2002) Interleukin-6-deficient mice develop mature-onset obesity. Nature Med 8, 75-79.

148. Wallenius K, Wallenius V, Sunter D, et al. (2002) Intracerebroventricular interleukin-6 treatment decreases body fat in rats. Biochem Biophys Res Commun 293, $560-565$.

149. Daniel JA, Elasser TH, Morrison CD, et al. (2003) Leptin, tumor necrosis factor- $\alpha$ (TNF), and CD14 in ovine adipose tissue and changes in circulating TNF in lean and fat sheep. J Anim Sci 81, 2590-2599.

150. Komatsu T, Itoh F, Hodate K, et al. (2005) Gene expression of resistin and TNF- $\alpha$ in adipose tissue of Japanese Black steers and Holstein steers. Anim Sci J 76, 567-573.

151. Harden LM, du Plessis I, Poole S, et al. (2006) Interleukin-6 and leptin mediate lipopolysaccharide-induced fever and sickness behavior. Physiol Behav 89, 146-155.

152. Bayliss WM \& Starling EH (1902) The mechanism of pancreatic secretion. J Physiol 28, 325-353.

153. Kojima M, Hosoda H, Date Y, et al. (1999) Ghrelin is a growth-hormone-releasing acylated peptide from stomach. Nature 402, 656-660.

154. Sugino T, Hasegawa Y, Kikkawa Y, et al. (2002) A transient ghrelin surge occurs just before feeding in a scheduled meal-fed sheep. Biochem Biophys Res Commun 295, 255-260.

155. Roche JR, Sheahan AJ, Chagas LM, et al. (2006) Short communication: genetic selection for milk production increases plasma ghrelin in dairy cows. J Dairy Sci 89, $3471-3475$.

156. Roche JR, Sheahan AJ, Chagas LM, et al. (2007) Concentrate supplementation reduces postprandial plasma ghrelin in grazing dairy cows. A possible neuroendocrine basis. J Dairy Sci 90, 1354-1363.

157. Nakazato M, Murakami N, Date Y, et al. (2001) A role for ghrelin in the central regulation of feeding. Nature 409, 194-198.

158. Wren AM, Seal LJ, Cohen MA, et al. (2001) Ghrelin enhances appetite and increases food intake in humans. $J$ Clin Endocrinol Metab 86, 5992-5995.

159. Wertz-Lutz AE, Knight TJ, Pritchard RH, et al. (2006) Circulating ghrelin concentrations fluctuate relative to nutritional status and influence feeding behaviour in cattle. $J$ Anim Sci 84, 3285-3300.

160. Harrison JL, Miller DW, Findlay PA, et al. (2007) Photoperiod influences the central effects of ghrelin on food intake, GH and LH secretion in sheep. Neuroendocrinology 87, 182-192.

161. Batterham RL, Le Roux CW, Cohen MA, et al. (2003) Pancreatic polypeptide reduces appetite and food intake in humans. J Clin Endocrinol Metabol 88, 3989-3992.

162. Tschop M, Smiley DL \& Heiman ML (2000) Ghrelin induces adiposity in rodents. Nature 407, 908-913.

163. Nogueiras R \& Tschop M (2005) Separation of conjoined hormones yields appetite rivals. Science 310, 985-986.

164. Stein LJ \& Woods SC (1982) Gastrin releasing peptide reduces meal size in rats. Peptides 3, 833-835.

165. Date Y, Murakami N, Toshinai K, et al. (2002) The role of the gastric afferent vagal nerve in ghrelin-induced feeding and growth hormone secretion in rats. Gastroenterology 123, 1120-1128.
166. Schwartz GH, McHugh PR \& Moran TH (1991) Integration of vagal afferent responses to gastric loads and cholecystokinin in rats. Am J Physiol 261, R64.

167. Gibbs J, Young RC \& Smith GP (1973) Cholecystokinin elicits satiety in rats with open gastric fisulas. Nature $\mathbf{2 4 5}$, 323-325.

168. Beinfield MC \& Palkovits M (1981) Distribution of cholecystokinin (CCK) in the hypothalamus and limbic system of the rat. Neuropeptides 2, 123-129.

169. Larsson LI \& Rehfeld JF (1978) Distribution of gastrin and CCK cells in the rat gastrointestinal tract. Histochem Cell Biol 58, 23-31.

170. Moran TH \& Kinzig KP (2004) Gastrointestinal satiety signals II. Cholecystokinin. Am J Physiol Gastrointest Liver Physiol 286, G183-G188.

171. Cummings DE \& Overduin J (2007) Gastrointestinal regulation of food intake. $J$ Clin Invest 117, 13-23.

172. Buchan AM, Polak JM, Solcia E, et al. (1978) Electron immunohistochemical evidence for the human intestinal I cell as the source of CCK. Gut 19, 403-407.

173. Reeve JR Jr, Eysselein VE, Ho FJ, et al. (1994) Natural and synthetic CCK-58. Novel reagents for studying cholecystokinin physiology. Ann N Y Acad Sci 713, 11-21.

174. Eng J, Li H-R \& Yalow RS (1990) Purification of bovine cholecystokinin-58 and sequencing of its $N$-terminus. Regul Pept 30, 15-19.

175. Little T, Horowitz M \& Feinle-Bisset C (2005) Role of cholecystokinin in appetite control and body weight regulation. Obes Rev 6, 297-306.

176. Choi B, Palmquist DL \& Allen MS (2000) Cholecystokinin mediates depression of feed intake in dairy cattle fed high fat diets. Domest Anim Endocrinol 19, 159-175.

177. Swanson KC, Benson JA, Matthews JC, et al. (2004) Pancreatic exocrine secretion and plasma concentration of some gastrointestinal hormones in response to abomasal infusion of starch hydrolyzate and/or casein. J Anim Sci 82, $1781-1787$.

178. Liddle R, Goldfine I, Rosen M, et al. (1985) Cholecystokinin bioactivity in human plasma. Molecular forms, responses to feeding, and relationship to gallbladder contraction. J Clin Invest 75, 1144-1152.

179. Schjoldager B, Molero X \& Miller LJ (1990) Gallbladder CCK receptors: species differences in glycosylation of similar protein cores. Regul Pept 28, 265-272.

180. Antin J, Gibbs J \& Smith GP (1975) Cholecystokinin interacts with pregastric food stimulation to elicit satiety in the rat. Physiol Behav 20, 67-70.

181. Moran TH \& McHugh PR (1982) Cholecystokinin suppresses food intake by inhibiting gastric emptying. Am J Physiol 242, R491-R497.

182. Zittel TT, Glatzle J, Kreis ME, et al. (1999) C-fos protein expression in the nucleus of the solitary tract correlates with cholecystokinin dose injected and food intake in rats. Brain Res 846, 1-11.

183. Edwards GL, Ladenheim EE \& Ritter RC (1986) Dorsomedial hindbrain participation in cholecystokinininduced satiety. Am J Physiol Regul Integr Comp Physiol 251, R971-R977.

184. Simon-Assmann PM, Yazigi R, Greeley GH Jr, et al. (1983) Biologic and radioimmunologic activity of cholecystokinin in regions of mammalian brains. $J$ Neurosci Res $\mathbf{1 0}$, $165-173$.

185. Farningham DAH, Mercer JG \& Lawrence AB (1993) Satiety signals in sheep: involvement of CCK, propionate and vagal CCK binding sites. Physiol Behav 54, 437-442.

186. Truett GE \& Parks EJ (2005) Ghrelin: its role in energy balance. J Nutr 135, 1313-1335. 
187. Neary NM, Small CJ, Wren AM, et al. (2004) Ghrelin increases energy intake in cancer patients with impaired appetite: acute, randomized, placebo-controlled trial. J Clin Endocinol Metab 89, 2832-2836.

188. Kamegai J, Tamura H, Shimizu T, et al. (2001) Regulation of the ghrelin gene: growth hormone-releasing hormone upregulates ghrelin mRNA in the pituitary. Endocrinology 142, 4154-4157.

189. Shintani M, Ogawa Y, Ebihara K, et al. (2001) Ghrelin, an endogenous growth hormone secratagogue, is a novel orexigenic peptide that antagonizes leptin action through the activation of hypothalamic neuropeptide $\mathrm{Y} / \mathrm{Y} 1$ receptor pathway. Diabetes 50, 227-232.

190. Cowley MA, Smith RG, Diano S, et al. (2003) The distribution and mechanism of action of ghrelin in the CNS demonstrates a novel hypothalamic circuit regulating energy homeostasis. Neuron 37, 649-661.

191. Kojima M \& Kangawa K (2005) Ghrelin: structure and function. Physiol Rev 85, 495-522.

192. Bagnasco M, Kalra PS \& Kalra SP (2002) Ghrelin and leptin pulse discharge in fed and fasted rats. Endocrinology 143, 726-729.

193. Kalra SP, Ueno N \& Kalra PS (2005) Stimulation of appetite by ghrelin is regulated by leptin restraint: peripheral and central sites of action. J Nutr 135, 1331-1335.

194. Murphy KG \& Bloom SR (2006) Gut hormones and the regulation of energy homeostasis. Nature 444, 854-859.

195. Hayashida T, Murakami K, Mogi K, et al. (2001) Ghrelin in domestic animals: distribution in stomach and its possible role. Domest Anim Endocrinol 21, 17-24.

196. Overduin J, Frayo RS, Grill HJ, et al. (2005) Role of the duodenum and macronutrient type in ghrelin regulation. Endocrinology 146, 845-850.

197. Hotta M, Ohwada R, Hideki K, et al. (2004) Plasma levels of intact and degraded ghrelin and their responses to glucose infusion in anorexia nervosa. J Clin Endocrinol Metab 89, 5707-5712.

198. McCowen KC, Maykel JA, Bistrian BR, et al. (2002) Circulating ghrelin concentrations are lowered by intravenous glucose or hyperinsulinemic euglycemic conditions in rodents. J Endocrinol 175, R7-R11.

199. Roche JR, Sheahan AJ \& Chagas LM (2008) Long-term infusions of ghrelin and obestatin in early lactation dairy cows. J Dairy Sci 91, 4728-4740.

200. Williams DL, Cummings DE, Grill HJ, et al. (2003) Mealrelated ghrelin suppression requires postgastric feedback. Endocrinology 144, 2765-2767.

201. Iqbal J, Kurose Y, Canny B, et al. (2006) Effects of central infusion of ghrelin on food intake and plasma levels of growth hormone, luteinizing hormone, prolactin, and cortisol secretion in sheep. Endocrinology 147, 510-519.

202. Theander-Carrillo C, Wiedmer P, Cettour-Rose P, et al. (2006) Ghrelin action in the brain controls adipocyte metabolism. J Clin Invest 116, 1983-1993.

203. Barazzoni R, Bosutti A, Stebel M, et al. (2005) Ghrelin regulates mitochondrial-lipid metabolism gene expression and tissue fat distribution in liver and skeletal muscle. Am J Physiol Endocrinol Metab 288, E228-E235.

204. Schaller G, Schmidt A, Pleiner J, et al. (2003) Plasma ghrelin concentrations are not regulated by glucose or insulin. Diabetes 52, 16-20.

205. Tschop M, Wawarta R, Riepl RL, et al. (2001) Post-prandial decrease of circulating human ghrelin levels. $J$ Endocrinol Invest 24, RC19-RC21.

206. Crowley WR, Ramoz G, Keefe KA, et al. (2005) Differential effects of methamphetamine on expression of neuropeptide Y mRNA in hypothalamus and on serum leptin and ghrelin concentrations in ad libitum-fed and schedule-fed rats. Neuroscience 132, 167-173.

207. Zhang JV, Ren P-G, Avsian-Kretchmer O, et al. (2005) Obestatin, a peptide encoded by the ghrelin gene, opposes ghrelin's effects on food intake. Science 310, 996-999.

208. Zizzari P, Longchamps R, Epelbaum J, et al. (2007) Obestatin partially affects ghrelin stimulation of food intake and growth hormone secretion in rodents. Endocrinology 148, 1648-1653.

209. Green BD, Irwin N \& Flatt PR (2007) Direct and indirect effects of obestatin peptides on food intake and the regulation of glucose homeostasis and insulin secretion in mice. Peptides 5, 981-987.

210. Samson WK, White MM, Price C, et al. (2007) Obestatin acts in brain to inhibit thirst. Am J Physiol Regul Integr Comp Physiol 292, R637-R643.

211. Holst B, Egerod KL, Schild E, et al. (2007) GPR39 signaling is stimulated by zinc ions but not by obestatin. Endocrinology 148, 13-20.

212. Nogueiras R, Pfluger P, Tovar S, et al. (2007) Effects of obestatin on energy balance and growth hormone secretion in rodents. Endocrinology 148, 21-26.

213. Pan W, Tu H \& Kastin AJ (2006) Differential BBB interactions of three ingestive peptides: obestatin, ghrelin, and adiponectin. Peptides 27, 911-916.

214. Chanoine JP, Wong AC \& Barrios V (2006) Obestatin, acylated and total ghrelin concentrations in the perinatal rat pancreas. Horm Res 66, 81-88.

215. Kim BJ, Carlson OD, Jang HJ, et al. (2005) Peptide YY is secreted after oral glucose administration in a gender specific manner. Clin Endocrinol Metab 90, 6665-6671.

216. Tatemoto K \& Mutt V (1980) Isolation of two novel candidate hormones using a chemical method for finding naturally occurring polypeptides. Nature $\mathbf{2 8 5}$, 417-418.

217. Stanley S, Wynne K \& Bloom S (2004) Gastrointestinal satiety signals III. Glucagon-like peptide 1, oxyntomodulin, peptide YY, and pancreatic polypeptide. Am J Physiol Gastrointest Liver Physiol 286, G693-G697.

218. Taylor IL (1993) Role of peptide YY in the endocrine control of digestion. J Dairy Sci 76, 2094-2101.

219. Batterham RL, Cowley MA, Small CJ, et al. (2002) Gut hormone PYY (3-36) physiologically inhibits food intake. Nature 418, 595-597.

220. Halatchev IG, Ellacot KLJ, Fan W, et al. (2004) Peptide $\mathrm{YY}_{3-36}$ inhibits food intake in mice through a melanocortin-4 receptor-independent mechanism. Endocrinology 145, 2585-2590.

221. le Roux CW, Batterham RL, Aylwin SJB, et al. (2006) Attenuated peptide YY release in obese subjects is associated with reduced satiety. Endocrinology 147, 3-8.

222. Bird AR, Croom WJ Jr, Fan YK, et al. (1996) Peptide regulation of intestinal glucose absorption. J Anim Sci 74, 2523-2540.

223. Bilchik AJ, Hines OJ, Zinner MJ, et al. (1994) Peptide YY augments postprandial small intestinal absorption in the conscious dog. Am J Surg 167, 570-574.

224. Hagan MM (2002) Peptide YY: a key mediator of orexigenic behaviour. Peptides 23, 377-382.

225. Miner JL, Della-Fera MA, Peterson JA, et al. (1989) Lateral cerebroventricular injection of neuropeptide Y stimulates feeding in sheep. Am J Physiol Regul Integr Comp Physiol 257, R383-R387.

226. Onaga T, Yoshida M, Inoue H, et al. (2000) Regional distribution and plasma concentration of peptide YY in sheep. Peptides 21, 655-667. 
227. Pagotto U, Marsicano G, Cota D, et al. (2006) The emerging role of the endocannabinoid system in endocrine regulation and energy balance. Endocr Rev 27, 73-100.

228. Kirkham TC \& Williams CM (1999) Central administration of anandamide induces hyperphagia in satiated rats. Soc Neurosci Abstr 25, 1885.

229. Breivogel CS \& Childers SR (1998) The functional neuroanatomy of brain cannabinoid receptors. Neurobiol Dis 5, 417-431.

230. Kirkham TC \& Williams CM (2001) Endogenous cannabinoids and appetite. Nutr Res Rev 14, 65-86.

231. Colombo G, Agabio R, Diaz G, et al. (1998) Appetite suppression and weight loss after the cannabinoid antagonist SR141716. Life Sci 63, PL113-PL117.

232. Simiand J, Keane M, Keane PE, et al. (1998) SR 141716, a CB1 cannabinoid receptor antagonist, selectively reduces sweet food intake in marmoset. Behav Pharmacol 9, $179-181$.

233. Fride E, Ginzburg Y, Breuer A, et al. (2001) Critical role of the endogenous cannabinoid system in mouse pup suckling and growth. Eur J Pharmacol 419, 207-214.

234. Williams CM, Rogers PJ \& Kirkham TC (1998) Hyperphagia in prefed rats following oral $\Delta^{9}$-THC. Physiol Behav 65, 343-346.

235. Mustafa AF, McKinnon JJ \& Christensen DA (1997) The nutritive value of hemp meal for ruminants. Can J Anim Sci 79, 91-95.

236. Williams CW \& Kirkham TC (1999) Anandamide induces overeating: mediation by central cannabinoid (CB1) receptors. Psychopharmcology 143, 315-317.

237. Gaetani S, Cuomo V \& Piomelli D (2003) Anandamide hydrolysis: a new target for anti-anxiety drugs? Trends $\mathrm{Mol}$ Med 9, 474-478.

238. Piomelli D, Beltramo M, Giuffrida A, et al. (1998) Endogenous cannabinoid signaling. Neurobiol Dis 5, $462-473$.

239. Julin Nielsen M, Petersen G, Astrup A, et al. (2004) Food intake is inhibited by oral oleoylethanolamide. J Lipid Res 45, 1027-1029.

240. Oveisi F, Gaetani S, Eng KT, et al. (2004) Oleoylethanolamide inhibits food intake in free-feeding rats after oral administration. Pharmacol Res 49, 461-466.

241. Wang X, Miyares RL \& Ahern GP (2005) Oleoylethanolamide excites vagal sensory neurones, induces visceral pain and reduces short-term food intake in mice via capsaicin receptor TRPV1. J Physiol 564, 541-547.

242. Di Marzo V, Melck D, Bisogno T, et al. (2001) Endocannabinoids: endogenous cannabinoid receptor ligands with neuromodulatory action. Tends Neurosci 21, 521-528.

243. Schwartz MW, Figlewicz DP, Baskin DG, et al. (1992) Insulin in the brain: a hormonal regulator of energy balance. Endocr Rev 13, 387-414.

244. Lobley GE (1992) Control of the metabolic fate of amino acids in ruminants: a review. J Anim Sci 70, 3264-3275.

245. Henry BA (2003) Links between the appetite regulating systems and the neuroendocrine hypothalamus: lessons from the sheep. J Neuroendocrinol 15, 697-709.

246. Woods SC, Lutz TA, Geary N, et al. (2006) Pancreatic signals controlling food intake; insulin, glucagon and amylin. Phil Trans $R$ Soc B 361, 1219-1235.

247. Bray GA (2000) Afferent signals regulating food intake. Proc Nutr Soc 59, 373-384.

248. Lopez M, Tovar S, Vazquez MJ, et al. (2007) Peripheral tissue-brain interactions in the regulation of food intake. Proc Nutr Soc 66, 131-155.

249. León HV, Hernandez-Ceron J, Keisler DH, et al. (2004) Plasma concentrations of leptin, insulin-like growth factor, and insulin in relation to changes in body condition score in heifers. J Anim Sci 82, 445-451.

250. Allen MS, Bradford BJ \& Harvatine KJ (2005) The cow as a model to study food intake regulation. Annu Rev Nutr $\mathbf{2 5}$, 523-547.

251. Herath CB, Reynolds GW, MacKenzie DDS, et al. (1999) Vagotomy suppresses cephalic phase insulin release in sheep. Exp Physiol 84, 559-569.

252. Kurose Y \& Terashima Y (2007) Roles of central histaminergic system in glucose metabolisms and food intake in sheep. Anim Sci J 78, 66-69.

253. Foster LA, Ames NK \& Emery RS (1991) Food intake and serum insulin responses to intraventricular infusions of insulin and IGF-I. Physiol Behav 50, 745-749.

254. Brüning JC, Gautam D, Burkes DJ, et al. (2000) Role of brain insulin receptor in control of body weight and reproduction. Science 289, 2122-2125.

255. Bareille N \& Faverdin P (1996) Modulation of the feeding response of lactating dairy cows to peripheral insulin administration with or without a glucose supply. Reprod Nutr Dev 36, 83-93.

256. Faverdin P \& Bareille N (1999) Lipostatic regulation of feed intake in ruminants. In Regulation of Feed Intake, pp. 89-102 [D van der Heide, EA Huisman, E Kanis, JWM Osse and MWA Verstegen, editors]. Wallingford, UK: CABI Publishing, chapter 11.

257. Deetz LE \& Wangsness PJ (1980) Effect of intrajugular administration of insulin on feed intake, plasma glucose and plasma insulin of sheep. J Nutr 110, 1976-1982.

258. Deetz LE \& Wangsness PJ (1981) Influence of intrajugular administration of insulin, glucagon and propionate on voluntary feed intake of sheep. J Anim Sci 53, 427-433.

259. Arase K, Fisler JS, Shargill NS, et al. (1988) Intracerebroventricular infusions of 3-OHB and insulin in a rat model of dietary obesity. Am J Physiol Regul Integr Comp Physiol 255, R974-R981.

260. Finglewicz DP (2003) Adiposity signals and food reward: expanding the CNS roles of insulin and leptin. Am J Physiol Integr Comp Physiol 284, R882-R892.

261. Baura GD, Schwartz MW, Foster DM, et al. (1993) Saturable transport of insulin from plasma into the central nervous system of dogs in vivo: a mechanism for regulated insulin delivery to the brain. J Clin Invest 92, $1824-1830$.

262. Woods SC \& Porte D Jr (1977) Relationship between plasma and cerebrospinal fluid insulin levels of dogs. Am J Physiol Gastrointest Liver Physiol 233, G331-G334.

263. Werther GA, Hogg A, Oldfield BJ, et al. (1987) Localization and characterization of insulin receptors in rat brain and pituitary gland using in vitro autoradiography and computerized densitometry. Endocrinology 121, $1562-1570$

264. Archer ZA, Rhind SM, Kyle CE, et al. (2005) Hypothalamic responses to peripheral glucose infusion in food-restricted sheep are influence by photoperiod. J Endocrinol 184, 515-525.

265. Porte D Jr, Baskin DG \& Schwartz MW (2002) Leptin and insulin action in the central nervous system. Nutr Rev $\mathbf{6 0}$, S20-S29.

266. Schwartz MW, Sipols AJ, Marks JL, et al. (1992) Inhibition of hypothalamic neuropeptide Y gene expression by insulin. Endocrinology 130, 3608-3616.

267. Benoit SC, Air EL, Coolen LM, et al. (2002) The catabolic action of insulin in the brain is mediated by melanocortins. $J$ Neurosci 22, 9048-9052.

268. Baskin DG, Figlewicz Lattemann D, Seeley RJ, et al. (1999) Insulin and leptin: dual adiposity signals to the brain for the 
regulation of food intake and body weight. Brain Res $\mathbf{8 4 8}$, $114-123$.

269. Air EL, Benoit SC, Clegg DJ, et al. (2002) Insulin and leptin combine additively to reduce food intake and body weight in rats. Endocrinology 143, 2449-2452.

270. Niswender KD \& Schwartz MW (2003) Insulin and leptin revisited: adiposity signals overlapping physiological and intracellular signalling capabilities. Front Neuroendocrinol 24, 1-10.

271. Carvalheira JBC, Siloto RMP, Ignacchitti I, et al. (2002) Insulin modulates leptin-induced STAT3 activation in rat hypothalamus. FEBS Lett 500, 119-124.

272. Saladin R, De Vos P, Guerre-Millo M, et al. (1995) Transient increase in obese gene expression after food intake or insulin administration. Nature 377, 527-529.

273. Tokuda T, Kimura D \& Fujihara T (2001) The relationship between leptin and insulin in blood plasma of growing lambs. Anim Sci 73, 71-76.

274. Lents CA, Wettermann RP, White FJ, et al. (2005) Influence of nutrient intake and body fat on concentrations of insulinlike growth factor-I, insulin, thyroxine, and leptin in plasma of gestating beef cows. J Anim Sci 83, 586-596.

275. Block SS, Rhoads RP, Bauman DE, et al. (2003) Demonstration of a role for insulin in the regulation of leptin in lactating dairy cows. J Dairy Sci 86, 3508-3515.

276. Leury BJ, Baumgard LH, Block SS, et al. (2003) Effect of insulin and growth hormone on plasma leptin in periparturient dairy cows. Am J Physiol Regul Integr Comp Physiol 285, R1107-R1115.

277. Amstalden M, Garcia MR, Stanko RL, et al. (2002) Central infusion of recombinant ovine leptin normalizes plasma insulin and stimulates a novel hypersecretion of luteinizing hormone after short-term fasting in mature beef cows. Biol Reprod 66, 1555-1561.

278. Roche JR, Sheahan AJ, Chagas LM, et al. (2008) Short communication: Change in plasma ghrelin in dairy cows following an intravenous glucose challenge. J Dairy Sci 91, 1005-1010.

279. Murata M, Okimura Y, Iida K, et al. (2002) Ghrelin modulates the downstream molecules of insulin signalling in hepatoma cells. J Biol Chem 277, 5667-5674.

280. Melendez P, Hofer CC \& Donovan GA (2006) Effect of ghrelin in dry matter intake and energy metabolism in prepartum sheep. A preliminary study. Theriogenology 66, 1961-1968.

281. Riedy CA, Chavez M, Figlewicz DP, et al. (1995) Central insulin enhances sensitivity to cholecystokinin. Physiol Behav 58, 755-760.

282. Bradford BJ \& Allen MS (2007) Depression in feed intake by a highly fermentable diet is related to plasma insulin concentration and insulin response to glucose infusion. $J$ Dairy Sci 90, 3838-3845.

283. She P, Hippen AR, Young JW, et al. (1999) Metabolic responses of lactating dairy cows to 14-day intravenous infusions of glucagon. J Dairy Sci 82, 1118-1127.

284. Jiang G \& Zhang BB (2003) Glucagon and regulation of glucose metabolism. Am J Physiol Endocrinol Metab 284, E671-E678.

285. de Jong A, Strubbe JH \& Steffens AB (1977) Hypothalamic influence on insulin and glucagon release in the rat. Am J Physiol Endocrinol Metab 233, E380-E388.

286. Geary N (1990) Pancreatic glucagon signals postprandial satiety. Neurosci Biobehav Rev 14, 323-338.

287. Langhans W, Zieger U, Scharrer E, et al. (1982) Stimulation of feeding in rats by intraperitoneal injection of antibodies to glucagon. Science 218, 894-896.
288. Martin JR, Novin D \& Vanderweele DA (1978) Loss of glucagon suppression of feeding after vagotomy in rats. Am J Physiol Endocrinol Metab 234, E314-E318.

289. Geary N \& Smith GP (1983) Selective hepatic vagotomy blocks pancreatic glucagon's satiety effect. Physiol Behav 31, 391-394.

290. Geary N, Le Sauter J \& Noh U (1993) Glucagon acts in the liver to control spontaneous meal size in rats. Am J Physiol Regul Integr Comp Physiol 264, R116-R122.

291. Weatherford SC \& Ritter S (1988) Lesion of vagal afferent terminals impairs glucagon-induced suppression of food intake. Physiol Behav 43, 645-650.

292. Sano H, Hattori N, Todome Y, et al. (1993) Plasma insulin and glucagon responses to intravenous infusion of propionate and their autonomic control in sheep. J Anim Sci 71, 3414-3422.

293. Kuhara T, Ikeda S, Ohneda A, et al. (1991) Effects of intravenous infusion of 17 amino acids on the secretion of $\mathrm{GH}$, glucagon, and insulin in sheep. Am J Physiol Endocrinol Metab 260, E21-E26.

294. Williams EL, Rodriguez SM, Beitz DC, et al. (2006) Effects of short-term glucagon administration on gluconeogenic enzymes in the liver of midlactation dairy cows. J Dairy Sci 89, 693-703.

295. Caldeira RM, Belo AT, Santos CC, et al. (2007) The effect of body condition score on blood metabolites and hormonal profiles in ewes. Small Rumin Res 68, 233-241.

296. Gedulin BR, Rink TJ \& Young AA (1997) Dose-response for glucagonostatic effect of amylin in rats. Metabolism 46, $67-70$.

297. Gedulin BR, Jodka CM, Herrmann K, et al. (2006) Role of endogenous amylin in glucagon secretion and gastric emptying in rats demonstrated with the selective antagonist, AC187. Regul Pept 137, 121-127.

298. Young A (1997) Role of amylin in nutrient intake - animal studies. Diabet Med 14, S14-S18.

299. Morley JE, Flood JF, Horowitz M, et al. (1994) Modulation of food intake by peripherally administered amylin. Am J Physiol Regul Integr Comp Physiol 267, R178-R184.

300. Rushing PA, Lutz TA, Seeley RJ, et al. (2000) Amylin and insulin interact to reduce food intake in rats. Horm Metab Res 32, 62-65.

301. Roth JD, Hughes H, Kendall E, et al. (2006) Antiobesity effects of the $\beta$-cell hormone amylin in diet-induced obese rats: effects on food intake, body weight, composition, energy expenditure, and gene expression. Endocrinology 147, 5855-5864.

302. Morris MJ \& Nguyen T (2001) Does neuropeptide Y contribute to the anorectic action of amylin? Peptides 22, 541-546.

303. Olsson M, Herrington MK, Reidelberger RD, et al. (2007) Comparison of the effects of chronic central administration and chronic peripheral administration of islet amyloid polypeptide on food intake and meal pattern in the rat. Peptides 28, 1416-1423.

304. Lutz TA, Geary N, Szabady MM, et al. (1995) Amylin decreases meal size in rats. Physiol Behav 58, 1197-1202.

305. Reidiger T, Schmid HA, Lutz T, et al. (2001) Amylin potently activates AP neurons possibly via formation of the excitatory second messenger cGMP. Am J Physiol Regul Integr Comp Physiol 281, R1833-R1843.

306. Reidiger T, Zuend D, Becskei C, et al. (2004) The anorectic hormone amylin contributes to feeding-related changes of neuronal activity in key structures of the gut-brain axis. Am J Physiol Regul Integr Comp Physiol 286, R114-R122. 
307. Cooper GJS (1994) Amylin compared with calcitonin generelated peptide: structure, biology and relevance to metabolic disease. Endocr Rev 15, 163-201.

308. Reda TK, Geliebter A \& Pi-Sunyer FX (2002) Amylin, food intake and obesity. Obes Res 10, 1087-1091.

309. Osto M, Weilinga PY, Alder B, et al. (2007) Modulation of the satiating effect of amylin by central ghrelin, leptin and insulin. Physiol Behav 91, 566-572.

310. Rushing PA, Hagan MM, Seeley RJ, et al. (2001) Inhibition of central amylin signaling increases food intake and body adiposity in rats. Endocrinology 142, 5035-5038.

311. del Prete E, Schade B, Reidiger T, et al. (2002) Effects of amylin and salmon calcitonin on feeding and drinking behaviour in pygmy goats. Physiol Behav 75, 593-599.

312. Min SH, Farr VC, Lee J, et al. (1999) Metabolic effects of amylin in lactating goats. J Anim Sci 77, 1241-1248.

313. Wynne K, Stanley S \& Bloom S (2004) The gut and regulation of body weight. J Clin Endocrinol Metab 89, 2576-2582

314. Adrian TE, Bloom SR, Bryant MG, et al. (1976) Distribution and release of human pancreatic polypeptide. Gut 17, 940-944.

315. Jesudason DR, Monteiro MP, McGowan BMC, et al. (2007) Low-dose pancreatic polypeptide inhibits food intake in man. Br J Nutr 97, 426-429.

316. Ueno N, Inui A, Iwamoto M, et al. (1999) Decreased food intake and body weight in pancreatic polypeptide-overexpressing mice. Gastroenterology 117, 1427-1432.

317. Asakawa A, Inui A, Yuzuriha H, et al. (2003) Characterization of the effects of pancreatic polypeptide in the regulation of energy balance. Gastroenterology 124, $1325-1336$.

318. Kojima S, Ueno N, Asakawa A, et al. (2007) A role for pancreatic polypeptide in feeding and body weight regulation. Peptides 28, 459-463.

319. Arosio M, Ronchi CL, Gebbia C, et al. (2003) Stimulatory effects of ghrelin on circulating somatostatin and pancreatic polypeptide levels. J Clin Endocrinol Metab 88, 701-704.

320. Dumont Y, Moyse E, Fournier A, et al. (2007) Distribution of peripherally injected peptide YY $\left(\left[{ }^{125} \mathrm{I}\right]\right.$ PYY $\left.(3-36)\right)$ and pancreatic polypeptide $\left(\left[{ }^{125} \mathrm{I}\right] \mathrm{hPP}\right)$ in the CNS: enrichment in the area postrema. J Mol Neurosci 33, 294-304.

321. Whitcomb DC, Puccio AM, Vigna SR, et al. (1997) Distribution of pancreatic polypeptide receptors in the rat brain. Brain Res 760, 137-149.

322. Larhammer D (1996) Structural diversity of receptors for neuropeptide Y, peptide YY and pancreatic polypeptide. Regul Pept 65, 165-174.

323. Nakajima M, Inui A, Teranishi A, et al. (1994) Effects of pancreatic polypeptide family peptides on feeding and learning behavior in mice. $J$ Pharmacol Exp Therapeutics 268, 1010-1014.

324. Clarke IJ, Backholer K \& Tilbrook AJ (2005) Y2 receptorselective agonist delays the estrogen-induced luteinizing hormone surge in ovariectomized ewes, but Y1-receptorselective agonist stimulates voluntary food intake. Endocrinology 146, 769-775.

325. Carter RR, Grovum WL \& Greenberg GR (1990) Parotid secretion patterns during meals and their relationships to the tonicity of body fluids and to gastrin and pancreatic polypeptide in sheep. Br J Nutr 63, 319-327.

326. Choi B \& Palmquist DL (1996) High fat diets increase plasma cholecystokinin and pancreatic polypeptide, and decrease plasma insulin and feed intake in lactating cows. J Nutr 126, 2913-2919.
327. Martin PA \& Faulkner A (1996) Effects of somatostatin-28 on circulating concentrations of insulin and gut hormones in sheep. J Endocrinol 151, 107-112.

328. Leshin LS, Barb CR, Kiser TE, et al. (1994) Growth hormone-releasing hormone and somatostatin neurons within the porcine and bovine hypothalamus. Neuroendocrinology 59, 251-264.

329. Willoughby JO, Oliver JR, Fletcher TP, et al. (1995) Distribution of somatostatin immunoreactivity in sheep hypothalamus: a comparison with that of the rat. Arch Histol Cytol 58, 31-36.

330. Stepanyan Z, Kocharyan A, Behrens M, et al. (2007) Somatostatin, a negative-regulator of central leptin action in the rat hypothalamus. J Neurochem 100, 468-478.

331. Watanobe H \& Habu S (2002) Leptin regulates growth hormone-releasing factor, somatostatin, and $\alpha$-melanocytestimulating hormone but not neuropeptide $\mathrm{Y}$ release in rat hypothalamus in vivo: relation with growth hormone secretion. J Neurosci 22, 6265-6271.

332. Matsunaga N, Arakawa NT, Goka T, et al. (1999) Effects of ruminal infusion of volatile fatty acids on plasma concentration of growth hormone and insulin in sheep. Domest Anim Endocrinol 17, 17-27.

333. Levine AS \& Morley JE (1982) Peripherally administered somatostatin reduces feeding by a vagal mediated mechanism. Pharmacol Biochem Behav 16, 897-902.

334. Ingvartsen KL \& Sejrsen K (1995) Effect of immunization against somatostatin (SS) in cattle - a review of performance, carcass composition and possible mode of action. Acta Agric Scand A Anim Sci 45, 124-131.

335. Henry BA, Rao A, Tilbrook AJ, et al. (2001) Chronic foodrestriction alters the expression of somatostatin and growth hormone-releasing hormone in the ovariectomised ewe. $J$ Endocrinol 170, R1-R5.

336. Mayo KE, Godfrey PA, Suhr ST, et al. (1995) Growth hormone-releasing hormone: synthesis and signalling. Recent Prog Horm Res 50, 35-73.

337. Chihara K, Minamitani N, Kaji H, et al. (1981) Intraventricularly injected growth hormone stimulates somatostatin release into rat hypophysial portal blood. Endocrinology 109, 2279-2281.

338. Katakami H, Downs TR \& Frohman LA (1987) Effect of hypophysectomy on hypothalamic growth hormone releasing factor content and release in the rat. Endocrinology 120, 1079-1082.

339. Chomczynski P, Downs TR \& Frohman LA (1988) Feedback regulation of growth hormone $(\mathrm{GH})$-releasing hormone gene expression by $\mathrm{GH}$ in rat hypothalamus. $\mathrm{Mol}$ Endocrinol 2, 236-241.

340. Minami S, Kamegai J, Sugihara H, et al. (1998) Growth hormone inhibits its own secretion by acting on the hypothalamus through its receptors on neuropeptide $\mathrm{Y}$ neurons in the arcuate nucleus and somatostatin neurons in the periventricular nucleus. Endocr $J$ 45, Suppl., S19-S26.

341. Rogers KV, Vician L, Steiner RA, et al. (1988) The effect of hypophysectomy and growth hormone administration on pre-prosomatostatin messenger ribonucleic acid in the periventricular nucleus of the rat hypothalamus. Endocrinology 122, 586-591.

342. Etherton TD \& Bauman DE (1998) Biology of somatotropin in growth and lactation of domestic animals. Physiol Rev 78, 745-761.

343. Peel CJ \& Bauman DE (1987) Somatotropin and lactation. J Dairy Sci 70, 474-486. 
344. Schneider HJ, Pagotto U \& Stalla GK (2003) Central effects of the somatotropic system. Eur $J$ Endocrinol 149, $377-392$.

345. Vaccarino FJ, Bloom FE, Rivier J, et al. (1985) Simulation of food intake in rats by centrally administered hypothalamic growth hormone-releasing factor. Nature 314, 167-168.

346. Vaccarino FJ \& Buckenham KE (1987) Naloxone blockage of growth-hormone releasing factor-induced feeding. Regul Pept 18, 165-171.

347. Vaccarino FJ, Feifel D, Rivier J, et al. (1988) Centrally administered hypothalamic growth hormone-releasing factor stimulates food intake in free-feeding rats. Peptides 9, 35-38.

348. Ruckebusch Y \& Malbert CH (1986) Stimulation and inhibition of food intake in sheep by centrally administered hypothalamic releasing factors. Life Sci 38, 929-934.

349. Riviere P \& Bueno L (1987) Influence of regimen and insulinemia on orexigenic effects of GRF(1-44) in sheep. Physiol Behav 39, 347-350.

350. Wehrenberg WB \& Ehlers CL (1986) Effects of growth hormone-releasing factor in the brain. Science $\mathbf{2 3 2}$ 1271-1273.

351. Vaccarino FJ \& Hayward M (1988) Microinjections of growth hormone-releasing factor into the medial preoptic area/suprachiasmatic nucleus region of the hypothalamus stimulate food intake in rats. Regul Pept 21, 21-28.

352. Dickson SL \& Luckman SM (1997) Induction of c-fos messenger ribonucleic acid in neuropeptide $\mathrm{Y}$ and growth hormone $(\mathrm{GH})$ releasing factor neurons in the rat arcuate nucleus following systemic injection of the $\mathrm{GH}$ secretagogue, GH-releasing peptide-6. Endocrinology 138, $771-777$.

353. Okada K, Ishii S, Minami S, et al. (1996) Intracerebroventricular administration of the growth hormone-releasing peptide KP-102 increases food intake in free-feeding rats. Endocrinology 137, 5155-5158.

354. Kuriyama H, Hotta M, Wakabayashi I, et al. (2000) A 6-day intracerebroventricular infusion of the growth hormonereleasing peptide KP-102 stimulates food intake in both non-stressed and intermittently-stressed rats. Neurosci Lett 282, 109-112.

355. Bowers CY (1996) Xenobiotic growth hormone secretagogues: growth hormone releasing peptides. In Growth Hormone Secretagogues, pp. 9-28 [BB Bercu and RF Walker, editors]. New York: Springer-Verlag.

356. Camanni F, Ghigo E \& Arvat E (1998) Growth hormonereleasing peptides and their analogs. Front Neuroendocrinol 19, 47-72.

357. Guillaume V, Magnan E, Cataldi M, et al. (1994) Growth hormone $(\mathrm{GH})$-releasing hormone secretion is stimulated by a new GH-releasing hexapeptide in sheep. Endocrinology 135, 1073-1076.

358. Locke W, Kirgis HD, Bowers CY, et al. (1995) Intracerebroventricular growth hormone-releasing peptide6 stimulates eating without affecting plasma growth hormone responses in rats. Life Sci 56, 1347-1352.

359. Tannenbaum GS, Guyda HJ \& Posner BI (1983) Negative feedback and body weight regulation via brain. Science $\mathbf{2 2 0}$, 77-79.

360. Lauterio TJ, Marson L, Daughaday WH, et al. (1987) Evidence for the role of insulin-like growth factor II (IGFII) in the control of food intake. Physiol Behav 40, $755-758$.
361. Melnyk RB \& Martin JM (1985) Insulin and central regulation of spontaneous fattening and weight loss. Am J Physiol 249, R203-R208.

362. Porte D \& Woods SC (1981) Regulation of food intake and body weight by insulin. Diabetologia 20, 274-280.

363. Woods SC, Lotter EC, McKay LD, et al. (1979) Chronic intracerebroventricular infusion of insulin reduces food intake and body weight of baboons. Nature 282, 503-505.

364. Woods SC, Stein LJ, McKay LD, et al. (1984) Suppression of food intake by intravenous nutrients and insulin in the baboon. Am J Physiol 247, R393-R401.

365. Breier BH (2006) Regulation of protein and energy metabolism by the somatotropic axis. Domest Anim Endocrinol 17, 209-218.

366. Sinclair KD, Lea RC, Rees WD, et al (2007) The developmental origins of health and disease: current theories and epigenetic mechanisms. In Reproduction in Domestic Ruminants VI, pp. 425-444 [JI Juengel, JF Murray and MF Smith, editors]. Nottingham, UK: Nottingham University Press.

367. Barker DJ \& Osmond C (1988) Low birth weight and hypertension. Br Med J 297, 134-135.

368. Barker DJ (2004) The developmental origins of chronic adult disease. Acta Paediatr Suppl 93, 26-33.

369. Oliver MH, Bloomfield FH, Harding JE, et al. (2006) The maternal, fetal and postnatal somatotrophic axes in intrauterine growth retardation. Biochem Soc Trans 27, 69-73.

370. Plagemann A (2006) Perinatal nutrition and hormonedependent programming of food intake. Horm Res $\mathbf{6 5}$, Suppl. 3, 83-89.

371. Oliver MH, Jaquiery AL, Bloomfield FH, et al. (2007) The effects of maternal nutrition around the time of conception on the health of the offspring. Soc Reprod Fertil 64, 397-410.

372. Cripps RL, Martin Gronert MS \& Ozanne SE (2005) Fetal and perinatal programming of appetite. Clin Sci 109, $1-11$.

373. Vickers MH, Breier BH, Cutfield WS, et al. (2000) Fetal origins of hyperphagia, obesity, and hypertension and postnatal amplification by hypercaloric nutrition. Am $J$ Physiol Endocrinol Metab 279, E83-E87.

374. Sibbald AM \& Davidson GC (1998) The effect of nutrition during early life on voluntary food intake by lambs between weaning and 2 years of age. Anim Sci 66, 691-703.

375. Ford SP, Hess BW, Schwope MM, et al. (2007) Maternal undernutrition during early to mid-gestation in the ewe results in altered growth, adiposity, and glucose tolerance in male offspring. J Anim Sci 85, 1285-1294.

376. Husted SM, Nielsen MO, Tygesen MP, et al. (2007) Programming of intermediate metabolism in young lambs affected by late gestational maternal undernourishment. Am J Physiol Endocrinol Metab 293, E548-E557.

377. Simmons RA, Templeton LJ \& Gertz SJ (2001) Intrauterine growth retardation leads to the development of type 2 diabetes in the rat. Diabetes 50, 2279-2286.

378. Bouret SG \& Simerly RB (2006) Developmental programming of hypothalamic feeding circuits. Clin Genet 70, 295-301.

379. Bouret SG, Draper SJ \& Simerly RB (2004) Trophic action of leptin on hypothalamic neurons that regulate feeding. Science 304, 108-110.

380. Feinle-Bisset C, Patterson M, Ghatei MA, et al. (2005) Fat digestion is required for suppression of ghrelin and stimulation of peptide YY and pancreatic polypeptide 
secretion by intraduodenal lipid. Am J Physiol Endocrinol Metab 289, E948-E953.

381. Trenkle A (1970) Effects of short-chain fatty acids, feeding, fasting and type of diet on plasma insulin levels in sheep. J Nutr 100, 1323-1330.

382. Leuvenink HG, Bleumer EJ, Bongers LJ, et al. (1997) Effect of short-term propionate infusion on feed intake and blood parameters in sheep. Am J Physiol 272, E997-E1001.

383. DiCostanzo A, Williams JE \& Keisler DH (1999) Effects of short- or long-term infusions of acetate or propionate on luteinizing hormone, insulin, and metabolite concentrations in beef heifers. J Anim Sci 77, 3050-3056.

384. Bell AW \& Bauman DE (1997) Adaptations of glucose metabolism during pregnancy and lactation. J Mammary Gland Biol Neoplasia 2, 265-278.
385. Duhlmeier R, Hacker A, Widdel A, et al. (2005) Mechanisms of insulin-dependent glucose transport into porcine and bovine skeletal muscle. Am J Physiol Regul Integr Comp Physiol 289, R187-R197.

386. Wester TJ, Lobley GE, Birnie LM, et al. (2000) Insulin stimulates phenylalanine uptake across the hind limb in fed lambs. J Nutr 130, 608-611.

387. Egan AR (1977) Nutritional status and intake regulation in sheep. VIII Relationships between the voluntary intake of herbage by sheep and the protein/energy ratio in the digestion product. Aust J Agric Res 28, 907-915.

388. Mbanya JN, Anil MH \& Forbes JM (1993) The voluntary intake of hay and silage by lactating cows in response to ruminal infusion of acetate or propionate, or both, with or without distension of the rumen by a balloon. Br J Nutr $\mathbf{6 9}$, $713-720$. 